University of Louisville

ThinkIR: The University of Louisville's Institutional Repository

Electronic Theses and Dissertations

$12-1999$

\title{
Elderly respondents' perceptions of patronizing speech by service providers toward elderly adults.
}

Tammi Rae La Tourette

University of Louisville

Follow this and additional works at: https://ir.library.louisville.edu/etd

Part of the Psychology Commons

\section{Recommended Citation}

La Tourette, Tammi Rae, "Elderly respondents' perceptions of patronizing speech by service providers toward elderly adults." (1999). Electronic Theses and Dissertations. Paper 3082.

https://doi.org/10.18297/etd/3082

This Master's Thesis is brought to you for free and open access by ThinkIR: The University of Louisville's Institutional Repository. It has been accepted for inclusion in Electronic Theses and Dissertations by an authorized administrator of ThinkIR: The University of Louisville's Institutional Repository. This title appears here courtesy of the author, who has retained all other copyrights. For more information, please contact thinkir@louisville.edu. 
By

Tammi Rae La Tourette

B.A., California State University San Marcos, 1995

\begin{abstract}
A Thesis
Submitted to the Faculty of the

Graduate School of the University of Louisville in Partial Fulfillment of the Requirements for the Degree of
\end{abstract}

Master of Arts

Department of Psychological and Brain Sciences

University of Louisville

Louisville, Kentucky

December 1999 


\section{ELDERLY RESPONDENTS' PERCEPTIONS OF PATRONIZING SPEECH BY SERVICE PROVIDERS TOWARD ELDERLY ADULTS}

By

Tammi Rae La Tourette

B.A., California State University San Marcos, 1995

A Thesis Approved on

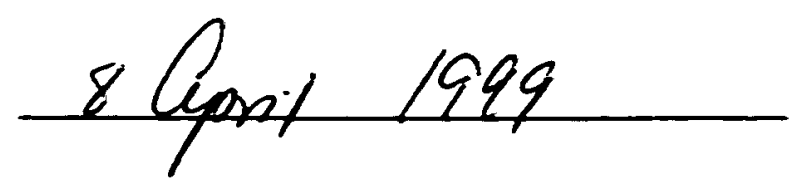

by the following Reading Committee:

Suzanne Meeks

Thesis Director

Stan Murrell

Greg Leichty 


\section{DEDICATION}

This thesis is dedicated to my husband

\section{Brett Robert La Tourette}

who has provided unfailing support in my educational endeavors. 


\section{ACKNOWLEDGMENTS}

I would like to thank my thesis chair and mentor, Dr. Suzanne Meeks, for her guidance and support of this research project. I would also like to thank the other committee members, Dr. Stan Murrell and Dr. Greg Leichty, for their comments and assistance. I would like to express my thanks to all of my research assistants, particularly, Fonda Wetmore who made it possible for me to finish this study in a timely manner. 


\begin{abstract}
This study examined the effects of several factors in elderly respondents' evaluations of neutral and patronizing speech by nurses toward elderly targets. Thirtyeight nursing home and 62 community Caucasian elderly women viewed two videotaped vignettes, one in which a nurse spoke to an elder target in a patronizing tone, and one with a neutral tone. Both samples rated the nurse more favorably, rated the elder target more satisfied with the conversation, and assumed that the nurse-elder dyad knew each other better when the nurse's speech was neutral as opposed to patronizing. Contrary to what was predicted, community elders did not rate patronizing speech any less favorably than did the nursing home sample. As predicted cognitive ability covaried significantly with speech ratings in both samples, such that speech style did not predict any unique variance in respondents' evaluations after accounting for the effects of cognitive ability. Cognitive ability predicted favorable ratings of neutral speech, but not negative ratings of patronizing speech. Contrary to what was predicted, length of institutionalization was not a significant factor in nursing home elders' speech style ratings. Community respondents rated the elder targets of patronizing speech as less competent and active/potent than the elder targets of neutral speech, suggesting a "blaming the victim" effect. In contrast to what was predicted, the target elder's residence was not a significant factor in community respondents' evaluations of speech styles or elder target's competence and activity/potency. However, the manipulation of the elder target's residence was most likely not salient enough to produce the predicted effect.
\end{abstract}




\section{TABLE OF CONTENTS}

INTRODUCTION AND LITERATURE REVIEW

PAGE

Functions of Speech.

Speech Accommodation Theory.

Communication Predicament Model of Aging.

Terminology and Characteristics of Overaccommodating Speech

Environmental and Social Influences on Patronizing

Speech.

Consequences of Overaccommodation

Perceptions of Overaccommodating Speech.

Hypotheses.

METHOD

Participants.

Vignettes.

Measures.

Procedure.

RESULTS

Effects of Respondents' Place of Dwelling.

Effects of Length of Institutionalization and Cognitive

Ability in Nursing Home Sample.

Effect of Cognitive Ability in the Community Sample.

Effect of Target Elder's Place of Dwelling

Preference for Neutral Speech.

Absence of Effect for Length of Institutionalization.........................

Effects of Cognitive Ability...

Effects of Speech Style on Community Respondents'

Perceptions of the Elder Target.

Future Directions.

Conclusions. 


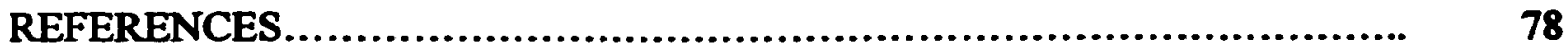

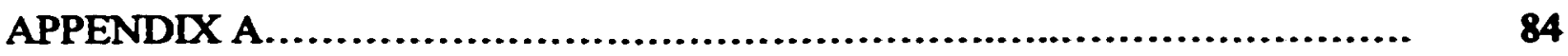

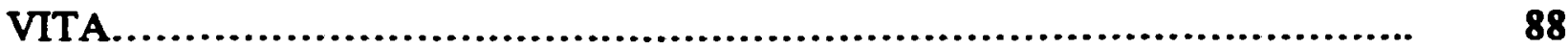




\section{LIST OF TABLES}

TABLE

PAGE

1. Sample Characteristics of Nursing Home and Community Participants for Age, Years of Education, and Cognitive Ability......................

2. Sample Characteristics for Nursing Home and Community Participants for Marital Status and Annual Income.

3. Speech Style Main Effects from the MANOVA Comparing Kentucky and California Community-Dwelling Older Adults.......................

4. Speech Style Main Effects from the MANOVA Comparing Speech Style Ratings of Nursing Home and Community Elders

5. Community and Nursing Home Respondents' Perceptions of How Well the Nurse and Elder Target Knew Each Other in the Patronizing and Neutral Vignettes

6. Speech Style Main Effects from the MANCOVA on Nursing Home Older Adults Examining the Effects of Speech Style, Length of Institutionalization and Cognitive Ability

7. Results from the Regression Analyses Examining Effects of Cognitive Ability and Length of Institutionalization on Ratings of Speech Styles within the Nursing Home Sample.

8. Results from the Regression Analyses Examining Effects of Cognitive Ability on Ratings of Speech Styles within the Community Sample.......

9. Speech Style Effects from the MANCOVA Comparing Community Elders' Perceptions of Speech Styles Based on the Elder Target's Place of Dwelling

10. The Effects of Speech Style and Target Elder's Residence on Community Respondents' Perceptions of How Well the Nurse and Target Elder Knew Each Other. 


\section{INTRODUCTION AND LITERATURE REVIEW}

Elderly adults are often the recipients of patronizing speech by younger adults, particularly their caregivers and those who provide them medical services (Giles, Fox, \& Smith, 1993). The Communication Predicament Model of Aging posits that younger adults change their style of speech toward older individuals based on their negative stereotypes of elders as a communicatively deficient group, often resulting in patronization rather than accommodation (Ryan, Giles, Bartollucci \& Henwood, 1986). Some researchers have suggested that this patronization fosters learned helplessness and dependency, resulting in accelerated mental and physical decline (Ryan et al., 1986). This, in turn, leads to a diminished quality of life and rapid depletion of monetary resources. There remain several unanswered questions as to how elderly individuals perceive what is thought to be patronizing speech and how living environment and cognitive ability play a role in this process. Because elderly adults currently constitute the fastest growing population in the United States and are living longer than ever, these issues require further study.

\section{Functions of Speech}

Communication, particularly speech, serves many functions in society. Speech is used not only to convey dominance and deference (McGee \& Barker, 1982), but also to communicate personal information such as status, competence, and social class (Stewart \& Ryan, 1982). Ryan et al. (1986) break speech into three aspects that constitute an 
incerpersonal message and convey information about the speaker: a) vocal aspects; b) linguistic aspects; and c) nonverbal aspects. Vocal aspects of an interpersonal message include nonlinguistic features such as voice quality that indicate social information such as status, age, and gender, and paralinguistic features such as intonation, pitch, and loudness. Nonverbal aspects of speech also include nonlinguistic features such as physical appearance and interpersonal distance, as well as paralinguistic features including gestures and facial expressions. The linguistic aspect of an interpersonal message refers to the content of the message itself.

Social gerontologists suggest that quantity and quality of communication opportunities are key to successful aging, and actually play a large role in the cognitive functioning of elderly people (Ryan et al., 1986). Wood \& Ryan (1991) posit that the quality of social relationships is constructed through speech along the dimensions of status (i.e. rank) and solidarity (i.e. closeness). Elderly people as a social group in Western civilization, although often remaining equal along the "solidarity" dimension, are commonly devalued on the "status" dimension. Contributing to this phenomenon is the fact that as individuals age, many experience challenges to effective communication such as hearing impairment, neurological disease, social isolation, poor sight, side effects from medication, normal age-related changes in cognitive functioning (e.g. decreased information processing speed and short-term memory difficulty), and age-related vocal changes, including decreases in loudness and a reduced rate of speech (Ryan et al., 1986). Although these challenges to effective communication exist for some individuals, elders are far from homogenous in this regard. 


\section{Speech Accommodation Theory}

The Speech Accommodation Theory (SAT) suggests that individuals adapt their style of speech when they wish to relate to and develop friendly relationships with others (Ryan et al., 1986). Coupland, Coupland, Giles, and Henwood (1988) posit that there are four strategies of speech accommodation employed by individuals depending on the goals of each conversational partner involved. Speech convergence refers to adapting one's speech to the speech of another in order to better relate to the interlocutor. Speech divergence is demonstrated by purposefully changing one's style of speech in order to present oneself as different from the interlocutor. Speech maintenance is neither convergence nor divergence. Speech complementarity is purposefully changing one's style of speech to accentuate valued differences.

Accommodating one's speech has many benefits in society. For example, accommodating speech toward children assists them in learning how to speak (Ferguson as cited in Ashburn \& Gordon, 1981). Speaking louder to individuals with hearing impairment allows for more successful communication (Ryan et al., 1986). Some studies indicate that institutionalized elderly adults prefer slower and more simplified speech than community-dwelling elders and young adults (Wood \& Ryan, 1991). Further, elders, more so than young adults, have been shown to benefit in their understanding of a message when their interlocutors emphasize through intonation the essential aspects of their interpersonal messages. (Ryan et al., 1986). However, as will be shown, younger individuals may mistakenly accommodate their speech based on stereotypes and expected communication abilities of their elderly conversational partners. 


\section{Communication Predicament Model of Aging}

The Communication Predicament Model of Aging (Ryan et al., 1986; Coupland et al., 1988) suggests that individuals often adapt their styles of speech based on stereotypes about elderly adults, which generally results in overaccommodation or patronization toward them and, subsequently, an unsuccessful communication encounter for both conversational partners (Harwood, Giles, Fox, Ryan, \& Williams, 1993) (see Figure 1). Elders are a common target of overaccommodation due to the numerous negative stereotypes held toward them and the fact that some elderly individuals do suffer challenges to effective communication (Caporeal, Lukaszewski, \& Culbertson, 1983; Ryan et al., 1986; Hummert \& Shaner, 1994).

As illustrated in Figure 1, the Communication Predicament Model of Aging indicates that overaccommodation results from the following processes: a) recognition of aging cues, such as voice quality, rate of speech, and physiognomic cues; and b) the aging cues elicit negative stereotypes, resulting in changes in style of speech (overaccommodation). How the elder responds to overaccommodation determines how the rest of the communication encounter will proceed (Coupland et al., 1988). The model predicts that a cooperative response from the elder will result in the reinforcement of negative stereotypes held by the younger aduit toward elderly people and an undesirable experience for the older adult. In contrast, an assertive response from the elder would result in either reinforcement of negative stereotypes (e.g. "shrew/curmudgeon") or the elicitation of positive stereotypes (e.g. "liberal patriarch/matriarch"), potentially resulting in a more positive and successful communication experience for both individuals and a 


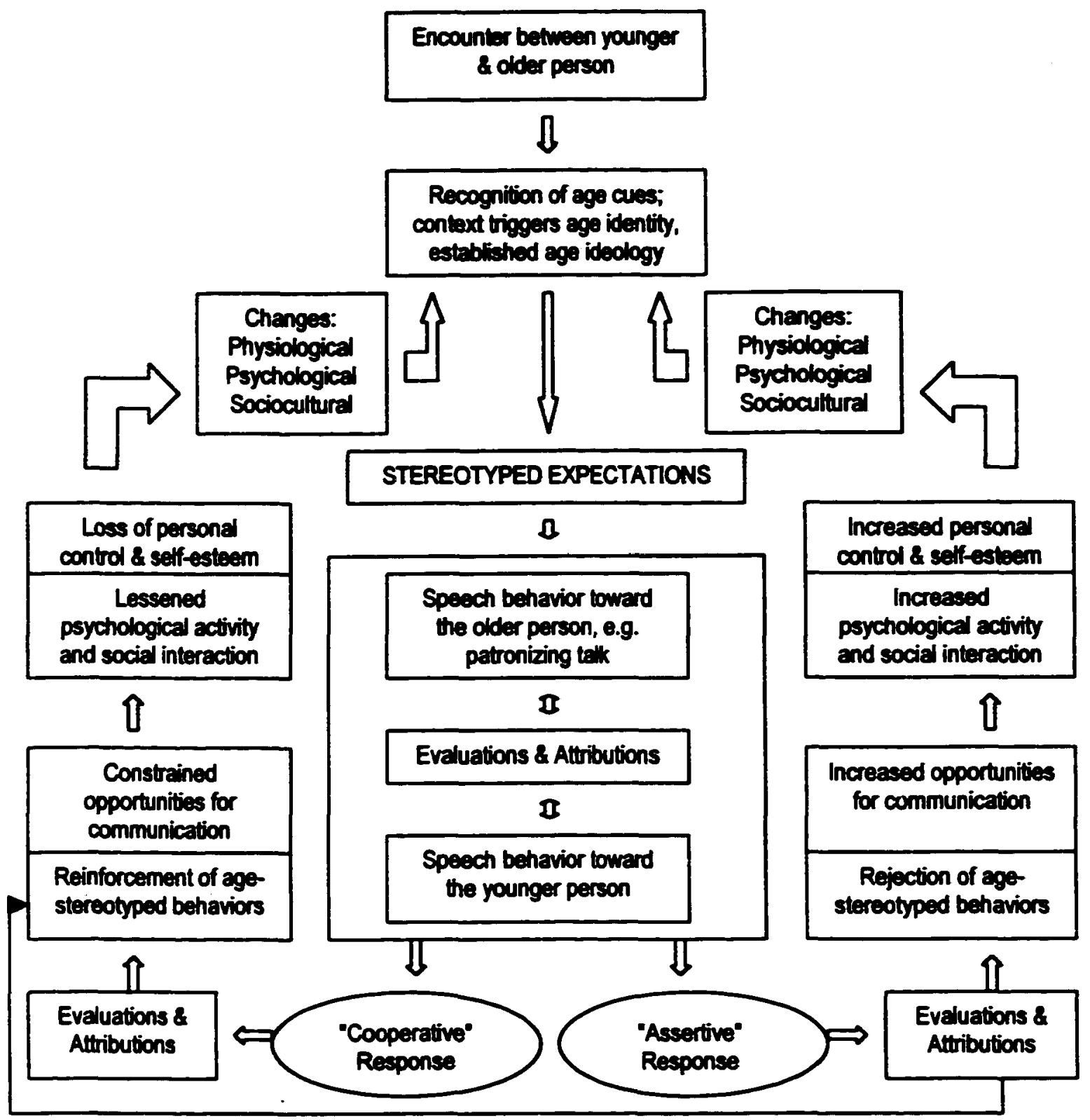

Figure 1

The Revised Communication Predicament Model of Aping

Source: From "Patronizing the young and elderly adults: Response strategies in a

community setting," by J. Harwood, H. Giles, S. Fox, E. B. Ryan, and A. Williams, 1993,

Research Reports, 21, p.213. Adapted with permission. 
greater sense of self-esteem and personal control for the elderly interlocutor.

Ryan et al. (1986) described four types of overaccommodation used by younger adults toward elderly adults: a) overaccommodation due to inferring cognitive deficits from physical and/or sensory handicaps; b) dependency-related overaccommodation such as overly-directive speech ("now you just get into that shower") and disciplinary speech ("naughty girl"); c) age-related divergence (e.g. excessively rapid speech or youth-cult slang) to enhance the differences between the two social groups; and d) intergroup overaccommodation as a result of assuming that elderly people are a homogenous and communicatively deficient group. All four of these types of overaccommodation reflect stereotypes about elderly people, however, there is more within-group difference among elders' abilities to communicate than there is between young adults and healthy older adults (Ryan et al., 1986).

Support for the Communication Predicament Model of Aging includes studies that have demonstrated that cues of aging do elicit stereotypes of elderly adults. Hummert and Shaner (1994) instructed young adults to sort various stereotyped traits of elderly people. They derived three positive categories (Perfect Grandparent, Liberal Matriarch/Patriarch, and John Wayne Conservative) and five negative categories (Severely Impaired, Shrew/Curmudgeon, Despondent, Recluse, and Vulnerable). Then, a second group of young adults viewed photographs of young-old and old-old elderly adults, and assigned to the photographs a combined list of traits adapted from the "Perfect Grandparent" and "Severely Impaired" categories. As expected, the old-old adults were 
assigned more traits from the "Severely Impaired" category than the young-old adults, indicating that physiognomic cues elicit stereotypes about elderly individuals.

To further support the Communication Predicament Model of Aging, the second group of young-adults in the study above were given the task of convincing (via an audiotaped message) the old-old elderly target who was supposedly in a nursing home, to tell a doctor about her stomach pains. They were also to persuade the young-old elderly target to attend her son's second wedding. The young adults expected the old-old elder's voice to sound older than the young-old elder's voice, and the subjects believed that accommodation would be more necessary for the old-old elder versus the young-old elder.

Furthermore, the recorded messages to the old-old elders contained more arguments and fewer words per utterance than messages to the young-old target, reflecting a simplified and adapted style of speech based on stereotypes of the institutionalized elder. This study was key in providing evidence for the validity of the Communication Predicament Model of Aging from the cues that elicit stereotypes to the actual overaccommodation demonstrated by the young adults. However, this study maximized the potential for negative stereotyping of the old-old target by indicating that she was in a nursing home. It is possible that overaccommodation may not have occurred if both the old-old target and young-old target were placed in a community context.

In a later study, Hummert (1994) had young adults categorize photos of older adults from magazines into the following age groups: young-old, middle-old, and oldold. Then, a second group of young-adults assigned traits, adapted from the eight 
stereotyped categories of elderly adults identified in the Hummert and Shaner (1994) study, to the photographs. Consistent with the Communication Predicament Model of Aging, young-old targets were assigned more positive stereotypes, middle-old were neither assigned more negative nor positive stereotypes, and the old-old were assigned more negative stereotypes. Although the expressions on the faces of the elderly targets may have influenced the assignment of both the age category and the negative stereotypes, this study demonstrates how physiognomic cues of aging elicit stereotypes.

A more recent study by Hummert, Shaner, Garstka, and Henry (1998) examined the influences of context, the older target's sex and stereotype (negative or positive), and the age of the respondent on communication toward the elderly. Respondents viewed photographs and read corresponding descriptions that were either positively or negatively stereotyped. Then, they rated how their speech might sound when talking to the target elder (e.g. how fast, hesitant, expressive, loud, etc...), and they audiotaped a persuasive message directed toward the elder. The negative stereotypes resulted in the belief that the respondents would accommodate more to these target elders than the positivelystereotyped elders. This was confirmed by the fact that the negatively-stereotyped elders received more overly nurturing and less affirming messages than the positivelystereotyped elders.

Interesting to note is that although a community context for the negativelystereotyped elder did little to affect speech styles toward him/her, a hospital context for the positively-stereotyped target elders resulted in a greater number of directive messages directed toward them by the respondents. That is, positive stereotypes are more likely to 
be downgraded by inconsistent and negative contexts, while negative stereotypes are not likely to be upgraded by positive contexts. In addition, older participants were less likely to accommodate speech based on stereotypes. The sex of the target did not significantly influence the style of speech directed toward him/her.

Thimm, Rademacher, and Kruse (1998) also had respondents audiotape messages to positively- and negatively-stereotyped elderly adults. In this case, however, all respondents were young (ages 22 to 28), and they were required to give instructions to both elderly and young targets on how to operate a radio alarm clock. Additionally, this study took place in Germany. When only the age was known about the targets (i.e. no stereotyped descriptions were provided), more patronizing features were found in speech toward the elder target versus the younger target, including more expectations of poor performance on the side of the elderly participants. More English words were used when speaking to positively-stereotyped elders versus negatively-stereotyped eldirs, suggesting that the respondents assumed that the more positively-stereotyped elders could understand and benefit from the use of English words better than negatively-stereotyped elders. There was also more discussion of age-related topics toward negatively-versus positively-stereotyped elder targets. However, the respondents did use more aspects of patronizing speech toward the positively-stereotyped elder than the young adult target, indicating that accommodation based on age still occurs despite the positive descriptions of the elderly adult.

Sachweh (1998) recorded, via audiotape, several interactions between nursing staff and residents in a German nursing home. The most typical recipients of secondary 
baby talk were female, frail, and either very much liked or very much disliked by the nursing staff. The influence of the elder target's sex contrasted the results of Hummert et al. (1998). However, this study (i.e. Sachweh, 1998) is much different in that it analyzed actual interactions within a nursing home setting versus the one-sided communication by the respondents toward a hypothetical elder target in the Hummert et al. (1998) study. Additionally, the Sachweh (1998) study took place in Germany in one particular nursing home. Clearly, more research is needed to further explore the effects of the elder target's sex.

Other studies have shown that speech characteristics act as cues of aging and subsequently result in stereotyping. Slower speech has been found to be associated with negative characteristics such as incompetence, less fluency, passivity, and weakness, and elderly adults tend to be evaluated in the same way as slower speakers (Stewart \& Ryan, 1982). Stewart and Ryan (1982) found that elders who spoke slowly were judged to be older than they were, and young adults rated them more negatively than fast-speaking young and elderly adults and slow-speaking young adults. However, the discrepancy between evaluations of young fast-speakers and young slow-speakers was significant, while there was little discrepancy between ratings of slow- and fast-speaking elderly adults, indicating that fast speech by elderly individuals does little to raise evaluations of them. This result is similar to that of Hummert et al. (1998) who also noted that additional positive cues such as context do little to upgrade the impressions of negativelystereotyped elders and their assumed need for accommodation. 
Williams and Giles (as cited in Giles et al., 1993) showed that older sounding speech tends to be devalued in terms of communicative competence. Giles, Coupland, Coupland, Williams, and Nussbaum (1992) indicated that speech serves as an age marker, and “...older people's sociolinguistic behavior is negatively evaluated, actively processed in a stereotypical manner, and memorized less effectively" (p. 277). These results suggest that quality of speech may even be a stronger cue of aging and elicitor of stereotypes than rate of speech.

\section{Terminology and Characteristics of Overaccommodating Speech}

Research in overaccommodating speech has employed numerous terms to describe the style of speech as well a variety of definitions. Ashburn and Gordon (1981) describe overaccommodation as "baby talk" (BT), which they defined as simplified speech in terms of mean length of utterance, complexity, number of imperatives and interrogatives, speech rate, repetition, and pronominal substitution. Caporeal et al. (1983) identified "secondary baby talk" as higher pitched speech with exaggerated intonation. Ryan et al. (1986) subdivided "intergroup over-accommodation" into the following: a) simplification processes that can be likened to BT mentioned above; b) clarification processes, referring to more careful articulation and higher level of explicitness; and c) an affective dimension which describes the demeaning emotional tone and dialect patterns accompanying the speech. All of the aspects of intergroup over-accommodation have also been referred to as "elderspeak" (Kemper, Vandeputte, Rice, Cheung, \& Gubarchuk, 1995). Ryan, Hummert, and Boich (1995) used "patronizing speech" to describe overaccommodation based on stereotyped expectations of elderly adults, and this 
definition is more closely aligned with the Communication Predicament Model of Aging. From the perspective of long-term care settings, overaccommodation has been described as "infantilization" and includes all actions and communications used to foster dependency in elderly adults (Dolinsky, 1984).

Ashburn and Gordon (1981) found that caregivers' speech toward elders (regardless of cognitive ability) in a residential care facility contained shorter mean length utterances, more imperatives, and was less complex than speech toward their peers. They also used more interrogatives toward the confused residents. Caporeal (1981) found that content-filtered BT or "secondary baby talk" (SBT; exaggerated intonation and high pitch devoid of actual speech content), extracted from actual audiotaped interactions between caregivers and elderly residents, is not distinguishable from content-filtered BT toward infants.

Culbertson and Caporeal (1983) studied differences among BT, non BT (NBT), and caregiver-peer styles of speech. In this study, BT was defined as exaggerated intonation and high-pitched speech (more like SBT) toward elders, and NBT was defined as normal intonation and pitch in speech toward elders. Live audiotaped interactions between elderly residents and caregivers showed that caregivers' speech toward peers was longer than both BT and NBT toward residents. Although no difference in sentence length was noted between BT and NBT, BT was more often used with offerings and encouragement than NBT. This study showed that speech toward elderly residents in a long-term-care facility is significantly more simplified than caregivers' speech to peers. Although NBT was supposedly not intended to be overaccommodating, it appears that 
talk toward elders in this study had an increasing magnitude of overaccommodation from simply less complex speech (NBT in this study) to less complex with exaggerated intonation, high pitch, and use of offerings and encouragement (BT in this study).

Another type of overaccommodation or patronization that is particularly common to institutionalized settings concerns forms of address. Wood and Ryan (1991) described four common forms of address that are often perceived as demeaning by residents. First, is the use of first names by staff who are strangers to the resident. Second, is dispensation where the staff mistakenly believe they are taking the appropriate action by asking residents how they wish to be addressed. However, the very act of asking infers that the caregivers ultimately have the power to give the residents the choice of what they would like to be called. Third, is the sarcastic use of the third person in place of the second person (e.g. "how is 'Mister' Jones today"), and, last is the use of first person plural in place of the second person (e.g. "and how are we today").

Other studies examining patronization of the young have identified three types of patronizing styles that may be applied to elderly adults including overparenting (seen as least offensive), nonlistening (interpreted as non-caring), and disapproving (seen as most offensive) (Giles \& Williams, 1994). Ryan et al. (1995) identified other typical patterns of patronization such as the frequent use of directives, closed-ended questions, ignoring concerns or invalidating concerns (e.g. you don't really want to do that), and labeling a concerned patient as a "bad patient." Other styles of patronization common to institutionalized settings include remarks such as "good girl," little inclusion of the residents' input into their own care plans, sending them to bed early, dressing them 
inappropriately (e.g. pigtails and bows), and not allowing them to exercise independence in tasks that they can accomplish by themselves.

Patronization is often presented with nonverbal behaviors. For example, a caregiver may feign deference by addressing the resident by title and surname, but then follow with patting the resident on the head (McGee \& Barker, 1982). Other nonverbal patronizing behaviors include looking away, frowning, stiff posture, gestures signaling impatience (e.g. watch-checking and foot-tapping), and inappropriate physical distance. In a study by Ryan, McLean, and Orange (1994), the most prominent nonverbal behaviors inferred from a written vignette in which a caregiver uses patronizing speech toward a resident were gentle movements, eye-rolling, lip-pursing, hands on hips, and repeatedly checking the time.

Although patronizing is particularly prevalent in institutionalized settings, it occurs in the community as well. Patronization in the community is most common in health care settings, but is also used by adult children toward their parents, and in public settings where elderly adults may move more slowly than younger adults (Hummert \& Mazloff as cited in Ryan et al., 1995). Characteristics of patronization in the community include over-parenting or overly-directive speech, nonverbal impatience, disrespectful/impersonal speech ("hey lady"), use of the exclusive "we," and oversimplification (Ryan et al., 1995).

\section{Environmental and Social Influences on Patronizing Speech}

The reason why patronization is so prominent in institutionalized settings may be explained by the Communication Predicament Model of Aging in that the aging cues are 
particularly salient in these settings and are more likely to elicit negative stereotypes of elderly individuals. Ashburn and Gordon (1981) suggest that staff may perceive caring for the residents as similar to taking care of children. McGee and Barker (1982) propose that when elders enter an institutionalized setting, they lose not only many of their belongings and familiar surroundings, but also their social status and the ability to care for themselves. Ryan et al. (1986) further describe the loss of power to make decisions and control their own lives that takes place upon entering an institution. All of these factors combined with the caregivers' dominance over them foster feelings of dependency and a decreased sense of well-being. The Communication Predicament Model of Aging would predict that these resulting feelings and behaviors lead to reinforcement of negative stereotypes of elderly people, increased overaccommodation by younger adults, and increased frustration for the elders.

The Communication Predicament Model of Aging is more likely to occur in intergenerational settings such as long-term care facilities and with unfamiliar conversational partners (Ryan et al., 1995). Health professionals often consider BT to be nurturing, and it may well be for a subpopulation of institutionalized residents (Caporeal as cited in Giles et al., 1993). Sachweh (1998) found that the typical user of secondary BT (SBT) in a German nursing home was middle-aged and female, and that in many cases it was perceived positively by the residents. Other caregivers may feel the need to "mother" the elderly recipients of care, while others still may use infantilization of elderly adults to guard against their own fears of aging (Dolinsky, 1984). Typically, though, long-term care settings lack individualized care and tend to apply a basic level of care to 
all residents regardless of their differing levels of ability (Dolinsky, 1984). This can be particularly detrimental for residents who are forced, due to insurance issues, to enter nursing facilities for rehabilitation (e.g. following hip replacement) and require an environment fostering empowerment and independence.

\section{Consequences of Overaccommodation}

Brody (as cited in Barton, Baltes, \& Orzech, 1980) describes the losses or "insults" to aging that may include loss or decrease of income, interpersonal losses of spouse, relatives, and peers, and decreases in physical and mental functioning. To enter an institution is also to admit having dependency needs in a society where individuals strive to achieve independence. Brody (1977) further discusses the need to normalize the dependency needs of elderly adults. Unlike childhood dependencies which are expected, acceptable, and relatively predictable, elderly individuals are highly variable, and the normal dependencies of aging have failed to be legitimized. This variability in needs and the motivation for long-term-care facilities to save time and expense, has led to the application of a basic level of care that tends to foster dependency in elderly adults rather than independence and self-care.

By virtue of becoming a care receiver in a long-term care facility, elderly individuals are at a distinct disadvantage in terms of status and power in their relationships with their caregivers (Ryan, Meredith, \& Shantz, 1994). Although overaccommodation of elderly adults may have a nurturing intent, it tends to emphasize the elders' loss of reciprocity, reducing their options to compliance and deference (Ryan, Hamilton, \& See, 1994). Caporeal (1981) agrees that infantilization of elderly adults 
fosters feelings of dependence and helplessness, particularly in long-term care settings. Ryan et al. (1986) further propose that such feelings of dependency and powerlessness, resulting from inhibition of the elders' physical and psychological potentials, lead to early mental and physical declines which further decrease quality of life and deplete social welfare and medical resources.

When elderly individuals are not given the opportunity to converse with others at a level consistent with their mental ability, one hypothesized consequence is that they are given the message that they are incompetent and incapable, and they learn that dependent rather than independent behaviors are reinforced (Ryan Meredith, et al., 1994). This, in turn, may lead to the loss of ability to voice their needs and become active participants in their own care, resulting in "feeling old" and learned helplessness. Emotionally, elderly people may not be able to tolerate the frustration and may succumb to the powerless role, leaving them with shallow dependent relationships with their caregivers (Dolinsky, 1984).

Lester and Baltes (1978) proposed an operant model of how dependency is fostered within institutions which supports many of the assertions of Ryan, Meredith et al. (1994) and Ryan et al. (1986). The Communication Predicament Model of Aging predicts that overaccommodation of elderly adults limits their successful interpersonal interactions, leaving them to respond either assertively or cooperatively to their interlocutors. Within an institution, it is assumed that tolerance of patronization (i.e. cooperation) is more likely because the elderly adults are dependent upon their caregivers. Lester and Baltes (1978) would suggest that this tolerance results from the 
reinforcement of dependent behaviors by staff. They would disagree that continual patronization results in learned helplessness because learned helplessness requires that the elders experience non contingent situations (Baltes \& Skinner, 1983).

Studies have consistently demonstrated that reinforcement of the residential behavior within institutions is more contingent upon dependent behaviors rather than independent behaviors (Lester \& Baltes, 1978; Baltes, Burgess, \& Stewart, 1980; Barton, Baltes, \& Orzech, 1980; Baltes, Honn, Barton, Orzech, \& Lago, 1983). In fact, dependent behaviors result in more continual reinforcement, whereas independent behaviors are followed by differential reinforcement of other behavior (Baites et al., 1980) or no response (Lester \& Baltes, 1978). Despite these consequences which expectedly extinguish independent behavior, the institutional residents still typically engage in more independent than dependent behaviors.

This finding may seem surprising at first glance, however, it may be explained by the fact that their observational coding system was more biased toward recording independent behavior (Baltes \& Reisenzein, 1986). For example, independent behaviors as small as the resident shifting his or her weight to help the nurse transfer him or her was recorded, as well as behaviors that occurred in the absence of social partners. Dependent behaviors, in contrast, required the presence of a social partner which is often quite limited in institutional settings and may have caused a ceiling effect. Also important to remember is that many independent self-care behaviors are well-learned, established behavior patterns that often occur in chains such that they do not require external reinforcement to maintain. The greater point to be understood, though, is that even when 
independent behaviors occur, they are rarely reinforced, while dependent behaviors are consistently reinforced.

The Communication Predicament Model of Aging and the operant model of dependency behavior are not mutually exclusive. The first model explains that a cooperative response leads to reinforcement of the staff's negative stereotypes of the elderly residents and decreases the elders' satisfaction with the interactions. This, in turn, leads to decreased quality of communication opportunities for them. Within an institution, however, dependent behaviors such as cooperation rather than assertion, are reinforced, placing elders in a "no-win" situation. If the residents respond assertively, they are not reinforced. If the residents respond cooperatively, they are reinforced by staff, but the interaction may result in feelings of inadequacy and frustration.

The operant model complements the Communication Predicament Model of Aging in that dependent behaviors (e.g. cooperative responses) result from reinforcement, and also help perpetuate the cycle of patronization. Because the residents' lives depend upon the staff"s care, it is in their interest to be "good patients." However, the price that they pay in terms of loss of self-control, independent decision-making, and self-esteem, may lead to accelerated mental and physical decline (Ryan et al., 1986). It therefore appears that within institutional environments, overaccommodation and the Communication Predicament Model of Aging may be one part of a larger operant system that reinforces and elicits dependency in elders.

One of the few, if not only, studies to examine the actual psychological consequences of overaccommodation and patronization is a recent study completed in 
China (Cai, Giles, and Noels, 1998). In this study both elderly adults' perceptions of inter- and intra-generational communication and its consequences for mental health were examined. Interestingly, the quality of their intra-generational communication seems to be the most important in terms of mental health, although communication with young family adults also appears to have significance as well. The respondents felt as though fellow elders were more likely to seem obligated to be polite to them than either young family or young non-family adults, and they also felt that other older adults were more nonaccommodative than the other two groups. In this particular study, nonaccommodation had a negative connotation.

The elder respondents also indicated that they felt less avoidant with young family adults versus older and non-family young adults, and that they felt more negative emotions with older adults than young family adults. Additionally, negative emotions experienced with other older adults were found to be a significant predictor of depression, and avoidance of intra-generational interactions was associated with greater self-esteem. The only inter-generational effects were that positive feelings experienced with young family adults predicted greater self-esteem, and nonaccommodation by young family adults was associated with greater symptoms of depression.

Therefore, intra-generational communication and inter-generational communication with young family members are associated with self-esteem and depression among Chinese elderly adults. Although the current study will be examining interactions between older and younger adults, the study by Cai et al. (1998) underscores the importance of quality communication opportunities for elderly adults. In addition, it 
supports the Communication Predicament Model of Aging by demonstrating the relationship between unsatisfying communication opportunities and negative psychological consequences.

\section{Perceptions of Overaccommodating Speech}

The effects of age. Studies that compare younger and older adults' perceptions of patronizing speech have shown that young adults typically rate patronizing speech more negatively than elderly adults. Edwards and Noller (1993) compared elderly adults', nursing students', and psychology students' evaluations of patronizing speech using videotaped nurse-elder interactions. Although the content of the speech remained the same, the six vignettes varied in that some contained a touch to the shoulder alone, an expression of endearment ("sweetie") alone, high pitch alone, or the combinations of touch/expression, touch/pitch, or pitch/expression. All three groups of respondents saw all of the vignettes and evaluated the pitch/expression vignette as the most patronizing. However, the elderly participants rated the expression/touch and pitch/expression vignettes as less patronizing than either of the two student groups. In terms of status ratings (i.e. the average of the "respectful" and "dominant" ratings) elderly adults also gave more positive ratings of the vignettes than the younger adults. Similarly, Ryan, Hamilton, et al. (1994) showed that older respondents consistently gave more positive evaluations of both neutral and patronizing speech styles. From these results, it seems clear that older respondents tend to rate speech, in general, more positively. Moreover, these results show that older adults do not typically evaluate patronizing speech as negatively as younger adults. 
One reason for these results might be that elderly respondents are more likely to blame the victim of patronizing speech than are younger respondents, thereby removing the responsibility from the patronizer and inferring communicative incompetence in the recipient of overaccommodation. In studies where respondents from the general population have rated the competence of the patronized elder, no blaming of the victim has been shown (Ryan et al., 1991; Ryan, MacLean, et al., 1994; Ryan, Meredith, et al., 1994). However, the majority of individuals in these studies have been young adults. Giles et al. (1993) found that elderly respondents, in comparison to younger respondents, perceive patronized institutionalized elders as more incompetent, weaker, and less alert. However, these results were not confirmed by Ryan, Hamilton, et al. (1994) or Hummert and Garstka (1996).

An alternative but complimentary reason for why older respondents rate patronizing speech less negatively than younger respondents could be because the patronized elders in the vignettes are always portrayed as institutionalized. In contrast, the elderly respondents in the studies are community-dwelling, and, as such, they may distinguish patronizing speech as more accommodative than overaccommodative to the institutionalized elderly targets than do the younger adults. It is possible that if the target elder was receiving patronizing speech from a caregiver in a community setting, as opposed to an institutionalized setting, not only may the elder be judged as more competent, but patronizing speech might also be evaluated more negatively.

Yet another reason for the age difference in ratings may be that elderly adults are more likely to have been the recipients of overaccommodation and have habituated to its 
patronizing qualities. This may explain the reason why young adults typically find it most offensive, followed by community-dwelling elderly adults, and then institutionalized elders who are likely to be patronized the most. There is also the possibility that agerelated cognitive decline may be the cause of age differences in ratings of patronizing speech. These alternative hypotheses will be examined in greater detail in the following sections.

The effects of increased level of care and institutionalization. Past research suggests that there is great variability in elderly individuals' perceptions of overaccommodating speech. One study found that elderly women receiving home health care in England perceived BT to have nurturing and caring qualities, although nearly half had indicated receiving demeaning speech elsewhere (Ryan et al., 1986). Yet other studies have indicated that elders prefer a neutral style of speech as opposed to the shrillness and exaggerated intonation accompanying overaccommodation (Ryan et al. 1986). In a survey conducted by Giles et al. (1993), $59 \%$ of community-dwelling elderly respondents indicated that they were recipients of patronizing speech, however, only $13 \%$ said that it occurred often, and $11 \%$ actually found it helpful (i.e. accommodating rather than overaccommodating).

Ryan et al. (1986) suggest that tolerance of overaccommodation will be more likely in situations where the elder is receiving voluntary care, when the elder is not capable of self-care, and in situations where there are lower expectations of elderly persons' competence in general. However, tolerance will be less likely by elders who feel younger than their years, and those who identify positively with elders as a social group 
and perceive its status as unfair and changeable. Consistent with that assumption, other studies have proposed that the more care required by the elder, the less negatively overaccommodating speech is evaluated. Increased dependency may even be related to perceptions of $\mathrm{BT}$ as nurturing.

Ryan and Cole (1990) showed that elderly residents of nursing facilities are more likely to perceive BT as nurturing than community-dwelling elders. In this study, however, the overall multivariate effect was not significant, and their interpretation of this particular univariate effect was to propose ideas for future research. Caporeal (1983) examined perceptions of BT in terms of content-filtered intonation. Although care receivers reported no particular preference for BT over non BT intonation and caregiverpeer speech intonation, elders at a skilled nursing facility showed a higher preference for BT than elders at a health care facility. Further, the functional ability of care receivers, as determined by multiple caregivers' ratings, was negatively correlated with the elders' preference for BT. The results of these studies suggest that although overaccommodating speech is perceived negatively by the general population and both the institutionalized and community-dwelling elderly adults, individuals with greater need for assisted care tend to show a higher tolerance for it, and some may even find it nurturing.

Another study compared community-dwelling and institutionalized elderly adults' ratings of patronizing speech using both written and audiotaped speech samples (Whitbourne, Culgin, \& Cassidy, 1995). Again, the difference between the communitydwelling elders' ratings of neutral and patronizing speech was significantly more negative than ratings by the institutionalized residents. However, similar to the results of Caporeal 
(1983), both institutionalized and community-dwelling elders showed a preference for adult speech which indicates that overaccommodation is not necessarily perceived as nurturing, even among institutionalized adults.

The effects of the length of institutionalization. Past literature has failed to examine whether elders come to prefer what seems patronizing as they age or whether it is a style of speech that they come to tolerate. This is particularly evident in studies that have measured institutionalized elders' perceptions of patronizing speech, but fail to examine how long they have been institutionalized. Upon entering an institutional environment, an elderly individual must adopt a new role and status from that which he or she identified with in the community (Ryan, Meredith, et al., 1994). in terms of the Communication Predicament Model, the community-dwelling elderly adults have little to risk and the most to gain by responding assertively to overaccommodation if they are offended by it.

In contrast, institutionalized elderly individuals may not have the luxury of responding assertively, as they are dependent upon the caregivers, and are more likely to respond cooperatively. In this case, a negative cycle results by which the elder's response reinforces the caregiver's stereotypes and overaccommodation continues to occur. It is most likely that institutionalization is a process by which elders must adapt to a new way of life, communication, and relationships, or as Lester and Baltes (1978) suggest, an operant process fostering increased dependency. If, indeed, elders learn to tolerate patronizing speech, as opposed to finding it more preferable, one would expect negative ratings of patronizing speech to attenuate as length of institutionalization increases. 
The effects of cognitive ability. Due to the difficulty in directly studying confused elders' evaluations of speech, most studies in this area have examined the general population's perceptions of overaccommodating speech toward alert and confused elderly institutionalized residents. Ryan, Bourhis, and Knops (1991) compared the general population's ratings of patronizing speech by nurses toward active/alert versus forgetful/confused elder targets using written vignettes. As expected, nurses using patronizing speech toward any resident were rated as less respectful, less nurturing, and more frustrated toward the elder. Patronized elders, regardless of cognitive ability, were rated as feeling more helpless, frustrated, warm, supportive and nurturing, and less dominant and patronizing toward the nurse. Contrary to what the Communication Predicament Model of Aging would predict, nurses were not more severely downgraded for patronizing the active/alert resident than the forgetful/confused resident.

Also contrasting what would be expected by the model, the active/alert elders were not expected to react more negatively to patronizing speech than the forgetful/confused residents. Similar results were found by Ryan, Meredith, et al. (1994) where patronizing speech was rated more negatively than neutral speech, and residents were rated as more satisfied with neutral speech than patronizing speech. Yet, again, no interactions between style of speech and cognitive ability of the elders resulted, indicating that individuals in the general population do not distinguish the appropriateness of overaccommodating speech in terms of the elders' cognition.

Giles et al. (1993) compared younger and older adults' ratings of patronizing speech based on written vignettes of nurse-resident interactions where the resident was 
said to be either alert or confused. Consistent with previous results, patronizing nurses were rated as being more dominant, helpless, patronizing, and frustrated, and less respectful, considerate, warm, and supportive toward the resident. In this study, the nurse using neutral speech toward the confused resident was rated as more nurturant and less helpless, and that these residents felt the least helpless in this scenario. This contradicts the Communication Predicament Model of Aging in that it predicts that patronizing would be more distasteful and inappropriate toward alert elders than mentally confused elders.

However, one must keep in mind that all of the studies described here have used outside observers to give their perceptions of patronizing speech, and they are likely not as accurate as actual evaluations by the elders themselves. An alternative explanation for these seemingly unexpected results is that all of these vignettes take place in institutions. The Communication Predicament Model of Aging posits that aging cues elicit stereotypes, resulting in overaccommodation. The institutionalized setting may already elicit stereotypes of incompetence, incapability, and dependence about the elderly target. Therefore, cognitive ability, as an independent variable, may do little more to add to the scenario.

Perhaps even normal age-related cognitive decline is responsible for the more positive ratings of patronizing speech by elderly adults versus younger adults, and institutionalized elders versus community-dwelling elders. There have been conflicting results as to whether cognitive ability influences evaluations of patronizing speech. Ryan et al. (1995) found that individuals from the general population evaluate patronizing 
speech less negatively when the recipient is cognitively confused rather than alert. Confused residents were rated as equally satisfied with patronizing and neutral speech, while alert residents were satisfied with only neutral speech. In a previous study Ryan et al.(1991) had participants from the general population rate vignettes in which patronizing or nonpatronizing speech was received by alert and confused institutionalized elderly adults from nurses. Contrary to the above results, patronizing speech was rated negatively regardless of the resident's level of cognitive ability.

As mentioned previously, some institutionalized elders report a preference for slower and more simplified speech (Wood \& Ryan, 1991), and some elderly adults report that what may seem to be overaccommodating speech is actually helpful (Giles et al., 1993). One major limitation of studies just described is that none of them examined the cognitive of ability of the respondents. If cognitive ability is an underlying factor in the evaluations of patronizing speech, then it should account for a significant amount of variability in ratings of speech styles.

In a recent discourse analysis of actual audiotaped interactions between nurses and residents in a German nursing home, the residents who were most explicit in their approval and disapproval of secondary baby talk were those with dementia (Sachweh, 1998). Although this study was one of the first to directly analyze this variable, it did not necessarily clarify the influence of cognitive ability on perceptions of patronizing speech.. Further, this study did not examine varying levels of cognitive status. Certainly, this relationship (or lack thereof) requires additional study. 


\section{Hypotheses}

To replicate prior results that community-dwelling elders evaluate patronizing speech more negatively than institutionalized elders, this study compared the perceptions of these two groups. Because past studies have shown group differences in ratings of both neutral and patronizing speech styles (Ryan, Hamilton, et al., 1994; Whitbourne et al., 1995), to controi for this variance, style of speech was a within-subjects factor. In all analyses pertaining to evaluative perceptions of speech styles, the lower the ratings, the more negatively speech was perceived. Perceptions of both neutral and patronizing speech styles were measured by the ratings of the elder target's satisfaction with the conversation, and how respectful, nurturing, benevolent, and competent the nurse was perceived to be.

$\mathrm{H}_{1}$ : In comparing the differences in ratings of neutral and patronizing speech, community-dwelling elderly respondents will rate patronizing speech more negatively than will institutionalized elders.

In order to determine whether or not institutionalized residents habituate to patronizing speech the longer they are institutionalized, the length of institutionalization was analyzed with respect to the residents' ratings.

$\mathrm{H}_{2}$ : Residents who have resided in an institution longer will rate patronizing speech more positively The fewer number of months the elderly respondents have resided within an institution the more negatively they will evaluate patronizing speech in comparison to neutral speech. 
Past studies have shown that community-dwelling elders tend to evaluate patronizing speech toward institutionalized elders more positively than younger adults (Edwards and Noller, 1993; Ryan, Hamilton, et al., 1994). Other research has shown that older adults tend to blame the victim of patronizing speech more so than do young adults (Giles et al., 1993). However, these studies are confounded by the fact that the elder target in the vignettes is typically an institutionalized resident of a long-term-care facility. The Communication Predicament Model of Aging would predict that the residence of the elderly recipient of patronizing speech plays a role in how negatively patronizing speech is evaluated. That is, an institutionalized setting would be more likely to elicit negative stereotypes about the elder target's competence than would a community setting. $\mathrm{H}_{3}$ : In comparing the difference in ratings between neutral and patronizing speech, community-dwelling elderly respondents will evaluate patronizing speech more negatively when the elder target in the vignette resides in a community rather than institutionalized setting.

$\mathrm{H}_{4}$ : Community-dwelling elders will evaluate the elder target of patronizing speech versus neutral speech as less competent and active/potent when the target resides in an institutional setting than when the target resides in the community.

Finally, the cognitive ability of the respondent has consistently been neglected in prior studies concerning evaluations of patronizing speech. Because some research has suggested that elders lower in cognitive ability may actually find overaccommodating speech to be, in fact, accommodating (Wood and Ryan, 1991; Giles et al., 1993), the 
effects of cognitive ability may be a significant factor influencing ratings of patronizing speech.

$H_{5}$ : Cognitive ability will account for a significant portion of variability within both the community and nursing home samples' evaluations of speech styles. 


\section{METHOD}

\section{Participants}

One hundred thirty-one individuals were invited to participate in this study, 74 residing in the community and 57 from nursing homes. All of the community elders agreed to participate, whereas 12 nursing home elders declined (no reasons given), leaving a total of 119 individuals who started the study. Of those, 114 completed the interview. Four of the "non-completers" were unable to continue their participation due to hearing and/or visual impairment. The other non-completer was too cognitively impaired to complete the study. Of those who completed the study, a total of 14 were excluded based on criteria which will be described later. The remaining 100 (62 community; 38 nursing home) who met full criteria for this study were included in the analyses. No compensation was awarded, however, a brief summary of the results was mailed to each participant once the study was completed.

\section{Nursing Home Sample}

Thirty-eight nursing home participants, recruited from eight nursing homes in northern Kentucky and southern Indiana, completed this study. Ages ranged from 63 to $98 \underline{M}=80.16, \underline{S D}=8.94)$, and years of education ranged from 6 to $16 \underline{M}=11.37$, $\underline{\mathrm{SD}}=2.35)$. The majority of women were widowed (76.3\%), while the rest were married (13.2\%), divorced (5.3\%), or never married (5.3\%). Annual income levels ranged from below $\$ 5,000$ to just under $\$ 35,000$, with $89.7 \%$ of the sample's income under $\$ 20,000$ 
(missing data for nine subjects). Participants had been institutionalized between 2 and 79 months $(M=24.42, \underline{S D}=19.84)$, and their cognitive ability as measured by the Short Portable Mental Status Questionnaire (SPMSQ; Pfeiffer, 1975) ranged from 4 to 10 $(\underline{M}=7.84, \underline{S D}=1.48)$. A summary of this sample's age, education, and cognitive ability descriptive statistics may be found in Table 1. Marital status and income levels are summarized in Table 2.

\section{Table 1}

Sample Characteristics of Nursing Home and Community Participants for Age, Years of Education, and Cognitive Ability

\begin{tabular}{|c|c|c|c|c|c|}
\hline & \multicolumn{2}{|c|}{ Nursing Home } & \multicolumn{2}{|c|}{ Community } & \multirow[b]{2}{*}{$t(98)$} \\
\hline & $\underline{\mathbf{M}}$ & $\underline{\text { SD }}$ & $\underline{\mathbf{M}}$ & $\underline{\text { SD }}$ & \\
\hline$\overline{\text { Age }}$ & 80.16 & 8.94 & 77.71 & 6.79 & $1.55 \mathrm{~ns}$ \\
\hline Years of Education & 11.37 & 2.35 & 12.84 & 2.85 & $-2.67 *$ \\
\hline Cognitive Ability & 7.84 & 1.48 & 8.74 & 1.01 & $-3.62 *$ \\
\hline
\end{tabular}


Table 2

Sample Characteristics for Nursing Home and Community Participants for Marital Status and Annual Income

\begin{tabular}{|c|c|c|}
\hline & $\begin{array}{c}\text { Nursing Home } \\
\underline{\mathrm{P}}\end{array}$ & $\begin{array}{c}\frac{\text { Community }}{\underline{P}} \\
\end{array}$ \\
\hline \multicolumn{3}{|c|}{ Marital Status $\chi^{2}(4)=9.15, \underline{\text { ns }}$} \\
\hline Married & $13.2 \%$ & $32.8 \%$ \\
\hline Divorced & $5.3 \%$ & $13.1 \%$ \\
\hline Never Married & $5.3 \%$ & $1.6 \%$ \\
\hline Separated & $0 \%$ & $1.3 \%$ \\
\hline \multicolumn{3}{|l|}{ Income $\chi^{2}(8)=15.92 *$} \\
\hline$<\$ 5,000$ & $27.6 \%$ & $0 \%$ \\
\hline$\$ 5,000-\$ 9,999$ & $34.5 \%$ & $30.0 \%$ \\
\hline$\$ 10,000-\$ 14,999$ & $20.7 \%$ & $27.5 \%$ \\
\hline$\$ 15,000-\$ 19,999$ & $6.9 \%$ & $12.5 \%$ \\
\hline$\$ 20,000-\$ 24,999$ & $6.9 \%$ & $15.0 \%$ \\
\hline$\$ 25,000-\$ 29,999$ & $0 \%$ & $5.0 \%$ \\
\hline$\$ 30,000-\$ 34,999$ & $3.4 \%$ & $5.0 \%$ \\
\hline$\$ 35,000-\$ 39,999$ & $0 \%$ & $0 \%$ \\
\hline$\$ 40,000-\$ 44,999$ & $0 \%$ & $2.5 \%$ \\
\hline$\$ 45,000+$ & $0 \%$ & $2.5 \%$ \\
\hline
\end{tabular}




\section{Community Sample}

Sixty-two elderly women from southem California $(\mathrm{n}=21)$ and northern Kentucky $(\underline{n}=41)$ composed the community sample. Ages ranged from 65 to $99 \underline{M}=77.71$, $\underline{\mathrm{SD}}=6.79)$ and years of education from 7 to $20 \mathrm{M}=12.84, \underline{\mathrm{SD}}=2.85)$. Cognitive ability scores on the SPMSQ ranged from 5 to 10 with a mean score of 8.74 (SD) $=1.01$ ) (see

Table 1). Independent samples t-tests were calculated to compare age, education, and cognitive ability in the Califomia (CA) and Kentucky (KY) samples. The only significant difference revealed was that CA elders in this sample were significantly more educated than the KY elders, $\underline{t}(60)=-3.28, \underline{p}<.05$. The mean education levels were 14.38 $(\mathrm{SD}=2.23)$ for $\mathrm{CA}$ elders and $12.05(\mathrm{SD}=2.84)$ for $\mathrm{KY}$ elders.

As in the nursing home sample, the majority of the community sample was widowed (50.8\%), the rest being married (32.8\%), divorced (13.1\%), separated (1.3\%), or never married (1.6\%) (see Table 2). There were no significant differences in marital status found between $\mathrm{CA}$ and $\mathrm{KY}$ samples, $\chi^{2}=6.903, \mathrm{p}>.05$. Annual income ranged between $\$ 5,000$ to under $\$ 45,000$ with $85 \%$ of the sample earning less than $\$ 25,000$ per year. Comparisons could not be made between $\mathrm{KY}$ and CA elders on income level due to the fact that only three of the $21 \mathrm{CA}$ respondents were willing to provide their annual income estimates, whereas only four of the $41 \mathrm{KY}$ elders declined to give their income. Comparison of the Nursing Home and Community Samples

Independent sampies t-tests comparing nursing home and community samples on age, education, and cognitive ability revealed significant differences in cognitive ability and years of education. Community-dwellers were more likely to have higher cognitive 
ability scores, $\underline{\mathrm{t}}(98)=-3.62, \mathrm{p}<.05$, and be more educated, $\underline{\mathrm{t}}(98)=-2.67, \mathrm{p}<.05$, than nursing home elders (see Table 1). Additionally, chi-square analyses of various income levels determined a significant difference between the samples, $\chi^{2}=15.92, \mathrm{p}<.05$. Upon closer examination, it appears that nursing home elders over-represent the lower income level ranges, whereas community elders are more evenly dispersed over the various income ranges (see Table 2). No significant differences in marital status were revealed between the two samples.

\section{Exclusionary Criteria}

Because women constitute the greatest proportion of the elderly population over 65 years of age, particularly those living within institutions, this study limited its participants to women over 65 years. The one exception to this was the inclusion of one 63-year-old woman from a nursing home. The sample was restricted to Caucasian women due to the fact that the nurse and elderly actresses in the videotaped vignettes were Caucasian women. Following each interview, the researchers rated the participants on reliability based on how well they understood the tasks of the study, particularly how to use the rating system. Those scoring "very good" (1) "good" (2) and "only fair" (3) were included in the analyses, whereas those rated "poor" (4) and "very poor" (5) were excluded. To insure a true community sample, only community-dwelling elders who have never lived in a nursing home for more than two weeks were included in this study. For the institutionalized group, only current long-term-care residents who had resided in nursing homes for at least two months were recruited for this study in order to insure a true institutionalized sample. 
Rationale for length of institutionalization criterion. There were two initial considerations in setting the length of institutionalization: a) because communitydwelling and institutionally-dwelling groups of elders were to be compared, it was important that the criterion be long enough such that the institutionalized sample was really "institutionalized"; and b) because length of institutionalization was a variable in the multiple regression, it was important to set the criterion short enough to capture the variability that would likely occur early on in the process of institutionalization.

Studies of the adaptation process of elderly adults to institutional settings have typically focused on adjustment and satisfaction following admission to nursing homes. Spasoff, Kraus, Beattie, Holden, Lawson, Rodenburg, and Woodcock (1978) studied the early response to institutional care by interviewing residents one month following admission to a nursing home (they also completed a follow-up at one year). They found that by the end of one month, "most residents appeared to have had rather realistic expectations of life in the institutions, and to have made a reasonably satisfactory adjustment to it" (p.286). Adjustment was measured as the comparison between the expectations of the residents and how it actually was, how bothered they were by the lack of privacy, how many brought personal possessions with them to institution, how many had made arrangements for obtaining regular spending money, what their level of activity was, and how satisfied they were with their care.

Joiner and Freudiger (1993) examined levels of adjustment and satisfaction of nursing home residents two months following placement. Their rationale for waiting two months was to "eliminate the initial period of adjustment" (p.74). This would imply that 
two months was long enough for initial adjustment to the institution to occur. Adjustment was measured by obtaining staff ratings and interviewing residents.

Brooke (1989) studied the progression of adaptation to institutional living by informally interviewing residents two to five times per week. She identified four phases of adaptation. The first is "disorganization" in which the residents are contending with past and present losses, some brought on by institutionalization and others exacerbated by institutionalization. By eight weeks, $90 \%$ of the residents had completed this phase. The second phase is "reorganization" which begins in the second to third month. The elders in this phase are dealing with "finding meaning in the experience of living in the nursing home" (p.67). The third phase, "relationship building" begins by about the third month and focuses on forming relationships and "engaging in conflicts with staff and residents" (p.67). The last phase, "stabilization," is typically completed within three to six months of admission. This is the phase in which the elders must conform to institutional living, but at the same time maintain their identity.

From these phases it would seem that the critical period of adjustment lasts roughly six months. Within the six months, there are several changes occurring at each phase, which implies that the most variability in residents' perceptions and behaviors would likely be within that time period, given that length of institutionalization is actually a factor in speech ratings. The criterion for institutionalization (two months) set in the present study represents a compromise in which the residents are past the initial shock of institutionalized living and are in the process of adapting to their new living environment. 


\section{Vienettes}

Each respondent viewed two videotaped vignettes that depicted an interaction taking place in a nurse's office in which a female elderly target ( 70 to 80 years old) is going to receive a flu shot from a younger female nurse (30 to 40 years old). Each participant viewed two interactions; one patronizing, and the other neutral. In each interaction the elder target's conversational script remained the same, while the nurse's script was either neutral or patronizing. Style of speech was a within-subjects variable such that each participant viewed both the patronizing and neutral versions of the vignette. The setting of the vignette, however, was a between-subjects variable in which each participant was randomly assigned to one of two vignette settings: nursing home or community. Therefore, each respondent, whether she lived in a nursing home or in the community, viewed two vignettes which varied the style of speech, but did not vary the setting of the interaction.

Because the respondents rated certain qualities about the nurse and the elder target after each vignette, two sets of actresses were required so that the actresses rated in the neutral vignettes were not the same as the actresses in the patronizing vignettes, and vice versa. Each elder and nurse dyad performed both a patronizing vignette as well as a neutral vignette, resulting in four total vignettes in this study. Subjects were randomly assigned to the two sets of actress pairs (i.e. the actresses in the vignettes), and the order of speech styles was counterbalanced, as well.

Patronizing speech style was operationally defined in this study as the use of exaggerated intonation, high pitch, less respectful forms of address (use of "Honey"), 
infantilizing content ("don't you look cute") and emotional tone ("we'll fix you up"), the use of the exclusive "we," overparenting, and demeaning nonverbal behavior (e.g. patting the elder's shoulder). The two sets of actresses portraying the nurse and elder improvised the dialogue causing them to differ only mildly. The exact dialogue and nonverbal behavior from all four vignettes are included in Appendix A. In both the neutral and patronizing vignettes, the nurse gently takes the arm of the elder to help her out of her chair. This was not intended to be patronizing, but was included in order to make the vignette believable when it was said to take place in the nursing home.

Neutral speech was defined in this study as the absence of patronization, or the opposite of the patronizing script. Neutral speech did not include exaggerated intonation nor any of the other demeaning qualities associated with the patronizing style. As a manipulation check (and "believability" check) for style of speech, experts in the field of gerontology, as well as several graduate research assistants in the field of aging, viewed the vignettes. Several versions of the vignettes were viewed and consensus was achieved on the selected vignettes for this study.

\section{Measures}

\section{Ratings}

Following viewing each vignette, the participants rated the nurse and elder. The interviewer presented each adjective to be rated on a $4 \times 6$ card and the respondents provided a rating between 1 and 7, one indicating "not at all" and 7 "very, very much". The rating scale consisted of seven thermometers depicting increasing degrees of "mercury" shaded in to indicate increasing degrees of the quality/adjective to be rated. 
Responses were recorded by the interviewers, including the primary investigator as well as four undergraduate research assistants. All respondents rated the elder target's satisfaction with the interaction and the nurse's respectful, nurturing, benevolent, and competent attributes. Participants also rated how realistic they believed the interaction to be and how well the nurse and elderly woman knew each other. In addition to the above ratings, community-dwelling respondents rated the elder target's competence and activity/potency. All ratings were completed twice, once following each vignette.

The rating system that was used in this study was adapted from Ryan et al. (1991), Ryan et al. (1994), and Ryan, Kennaley, Pratt, and Shumovich (1996). "Respect" was measured by averaging the 7-point ratings of how respectful, controlling, and patronizing the nurse was toward the elder in the vignette. Nurturance consisted of the average rating of how caring, cold, and nurturing the nurse was toward the elder. Benevolence, in kind, was the average rating of how unfriendly, trustworthy, and helpful the nurse in the vignette was. Competence of the nurse was measured by taking the average rating for how competent and insecure the nurse was. The elder target's satisfaction with the conversation was also measured by averaging the ratings of how satisfied and frustrated she was with the conversation. The lower the rating, the less nurturing, respectful, benevolent, and competent the nurse was, and the less satisfied with the conversation the elder target was. Reverse scoring was applied to the following ratings: controlling, patronizing, unfriendly, cold, insecure, and frustrated.

In addition to the ratings described above, community respondents also rated the attributes of the elder target in the vignettes in terms of competence and activity-potency. 
The target elder's competence was quantified in the same manner as the nurse's competence, and activity-potency was the average rating of how active and confused the elder target was (reverse-scoring for "confused"). Ryan et al. (1991) did not average the ratings, but rather performed separate analyses for each of the ratings. To minimize experiment-wise error this study averaged the ratings under each attribute (i.e. average the ratings of several adjectives). Again, the lower the rating, the less competent and active/potent the elder was perceived to be.

Two additional ratings were obtained to measure how realistic the vignettes were perceived to be and how well the nurses and elders in the vignettes were believed to have known each other. These ratings were not part of the original hypotheses, but were taken in order to perform additional analyses to aid in the interpretation of the results. These ratings will be referred to later in the results.

The Short Portable Mental Status Questionnaire (SPMSO)

The SPMSQ (Pfeiffer, 1975) is a 10-item instrument that assesses areas of cognitive functioning including orientation to place and time, general and personal knowledge, concentration, and set-shifting (i.e. counting backwards by 3s). Responses are coded either " 0 " for an incorrect response or " 1 " for a correct response, with a total score ranging from zero to 10 points, higher scores corresponding to higher levels of cognitive functioning. The criterion levels for intellectual impairment follow: a) a score of zero to two points corresponds to severe intellectual impairment; b) a score of three to five points reflects moderate intellectual impairment; c) a score of six to seven points indicates mild intellectual impairment; and d) a score of eight to ten points corresponds to intact 
intellectual functioning. To control for variability due to differences in education levels, individuals with only a grade school education are allowed one more error, and those with an education beyond high school are allowed one less error.

Validity studies of the SPMSQ have indicated adequate criterion-related validity with clinical diagnosis between .63 and .92 , with stronger predictive validity as impairment increases (Pfeiffer, 1975; Haglund \& Schuckit, 1976; Foreman, 1987). Internal consistency has been reported at .90 (Foreman, 1987), and test-retest reliability with an interval of four weeks has been established between .82 and .83 (Pfeiffer, 1975). The adequate reliability and validity statistics coupled with its quick and easy administration, made the SPMSQ the most efficient tool to screen for cognitive impairment in this study.

\section{Procedure}

Each participant was required to sign a statement of consent to participate in the study. The participants were asked for basic demographic information regarding their age, ethnicity, and years of education, as well as a history of where they have lived and for how long. Then, each individual was administered the SPMSQ. Each person participated individually in this study, rather than in a group. Following each interview, the interviewers recorded whether or not the participant completed the interview, and, if not, for what reasons. Additionally, the quality of interview data was rated as "very good" (1), "good" (2), "only fair" (3), "poor" (4), and "very poor" (5), and miscellaneous comments regarding the interview were recorded. 
The order of speech styles (patronizing and neutral) was counterbalanced to control for order effects, and the setting in which the vignettes took place was described to the subjects. The order of actresses was also varied such that no one pair of actresses was always viewed in the patronizing or neutral interaction. The elder target's script was held constant to help control for added variance in ratings due to different conversational scripts. The purpose of using style of speech as a within-subjects variable was to help control for some of the error variance due to individual differences in speech ratings. That is, some individuals rate speech, in general, more highly than others, which can diminish main effects and interactions between groups of elders. This study is more concerned with determining how much more negatively patronizing speech is perceived relative to neutral speech.

Prior to viewing each vignette the respondents randomly assigned to the community setting condition were informed that they would be watching a brief conversation between a nurse and an older woman who has come to a community health care center to receive a flu shot. In the institutionalized setting condition, the participants were told that they would be viewing a conversation taking place in a nursing home between a nurse and an older woman who is to receive a flu shot. Following the viewing of each vignette, the tape was stopped, and the evaluations were recorded. 


\section{RESULTS}

To avoid redundancy, aspects that are common to most or all analyses will be discussed first, followed by a description of the specific analyses that were used to test each hypothesis. Wilks' lambda and its associated $\mathrm{E}$ value was used to interpret multivariate effects, and the alpha level was set at .05 for all analyses. As mentioned previously, each respondent viewed two vignettes where style of speech (i.e. neutral versus patronizing) was a within-subjects variable. Therefore, rather than examining perceptions of each style of speech separately, the differences between ratings of neutral and patronizing speech were analyzed in testing all hypotheses. In testing the hypotheses that involve evaluative perceptions of speech style (i.e. hypotheses $1,2,3$, and 5), the following five dependent variables were included: a) "satisfaction" or the perceived satisfaction of the elder target with the conversation; b) "respect" or how respectful the nurse is perceived to be; c) "nurturance" or the perceived nurturing qualities of the nurse; d) "benevolence" or the perceived benevolence of the nurse; and e) "nurse's competence" or the perceived competence of the nurse. The ratings that were averaged to comprise each of these five dependent variables were discussed earlier.

During data collection, it quickly became apparent that several elderly adults did not understand the adjectives "controlling" and "patronizing," often perceiving these qualities to be positive in meaning when a negative connotation was intended. These adjectives compose two of the three ratings that are averaged to obtain the overall rating 
for "respect." Because of the continual misunderstanding of these terms, "respect" was revised to include only the rating for "respect" thereby removing the "controlling" and "patronizing" ratings. Separate analyses using the revised "respect" ratings were performed following each of the primary analyses with the non-revised "respect" ratings.

Recall that there were two sets of actresses that performed in each a neutral and patronizing vignette, and that each subject viewed both speech styles and both actress pairs. One particular respondent could watch Nurse $A$ in the patronizing condition and Nurse B in the neutral condition. Similarly, another respondent could view Nurse $A$ in the neutral context and Nurse B in the patronizing context. Additionally, subjects were randomly assigned to the two different settings in which the vignettes were said to have taken place, nursing home or community health care center. The order of speech styles was also counterbalanced such that the respondents either viewed the patronizing vignette first or the patronizing vignette second. Chi-square analyses were used to determine whether counterbalancing and random assignment was successful between and within nursing home and community samples. Comparisons of nursing home and community samples revealed no significant differences in the distributions of order, $\left[\chi^{2}(1)=1.79, p\right.$ $>.05]$, actress pair $\left[\chi^{2}(1)=0.59, \mathrm{p}>.05\right]$, or setting $\left[\chi^{2}(1)=0.002, \mathrm{p}>.05\right]$. Similarly, no significant differences were found between community elders in California and those in Kentucky for order, $\left[\chi^{2}(1)=0.196, p>.05\right]$, actress pair $\left[\chi^{2}(1)=0.65, p>.05\right]$, or setting $\left[\chi^{2}(1)=1.79, \mathrm{p}>.05\right]$.

A manipulation check was performed to determine how realistic the nurse-elder conversations were. Each subject rated the vignettes on a scale from 1 ("not at all 
realistic") to 7 ("very, very much realistic"). Nursing home elders gave a mean rating of $5.90(\mathrm{SD}=1.49)$ to the patronizing vignettes and a mean rating of $5.84(\mathrm{SD}=1.41)$ to the neutral vignettes. Community elders gave mean ratings of $5.63(\mathrm{SD}=1.57)$ to the patronizing vignettes and $6.03(\mathrm{SD}=1.29)$ to the neutral vignettes. The magnitude of these ratings suggests that the vignettes were, on average, perceived to be fairly realistic. A 2 (speech styie) X 2 (respondent's place of dwelling) repeated-measures ANOVA did not determine any significant main effects for speech style $[E(1,98)=1.06, \mathfrak{p}>.05]$ or respondent's place of dwelling $[F(1,98)=0.02, p>.05]$ on how realistic the vignette were perceived to be. Similarly, no significant interaction between speech style and respondent's place of dwelling was found, $F(1,98)=1.80, p>.05$.

\section{Effects of Respondents' Place of Dwelling}

Initial analyses were calculated to determine any differences in the quality of interview data between nursing home and community-dwelling elders. An independent samples t-test indicated that community elders were significantly more reliable than their nursing home counterparts, $\underline{t}(98)=2.93, \underline{p}<.05$. Additionally, before comparing nursing home and community elders, a preliminary analysis was performed on the CA and KY community samples to determine any significant differences in ratings. A 2 (speech style) X 2 (actress pair) X 2 (speech style order) X 2 (state of residence) repeated-measures MANOVA was calculated on the five dependent variables associated with evaluative perceptions of speech style. The independent variables of actress pair and speech style order were included to assess actress effects and order effects, and speech style served as the repeated-measure. 
The MANOVA determined overall significant differences for speech style and state of residence, $\mathrm{F}(5,50)=10.42, \mathrm{p}<.05$, and $\underline{F}(5,50)=2.80, \mathrm{p}<.05$, respectively. Univariate tests revealed that speech style was significant for the dependent variables of "respect," "benevolence," "nurturance," and "satisfaction," but not "nurse's competence." The means for these groups are shown in Table 3. Regardless of whether community elders live in Califormia (CA) or Kentucky (KY), neutral speech as opposed to

Table 3

Speech Style Main Effects from the MANOVA Comparing Kentucky and California Community-Dwelling Older Adults.

\section{Speech Style}

Patronizing Neutral

$\begin{array}{llllll}\text { Dependent Variables } & \underline{M} & \underline{\text { SD }} & \underline{\mathrm{M}} & \underline{\mathrm{SD}} & \underline{\mathrm{F}}(1,54)\end{array}$

Nurse

$\begin{array}{lccccc}\text { Respect } & 3.76 & 1.42 & 5.41 & 1.37 & 27.53^{*} \\ \text { Nurturance } & 5.21 & 1.50 & 5.98 & 1.11 & 7.10^{*} \\ \text { Benevolence } & 5.68 & 1.18 & 6.29 & 0.83 & 7.85^{*} \\ \text { Competence } & 6.07 & 1.25 & 6.48 & 0.73 & 4.00\end{array}$

Elder
Satisfaction
$4.94 \quad 1.53$
$6.38 \quad 0.99$
$38.16^{*}$

q $<.05$. 
patronizing speech resulted in higher ratings of the nurse's respect, benevolence, and nurturance, and higher ratings of the elder target's satisfaction with the conversation. None of the univariate tests for state of residence were significant for any of the five dependent variables.

The same MANOVA calculated with the revised "respect" ratings produced similar effects for speech style, however, the overall effect for state of residence was no longer significant. Most likely, the difference in education levels between the CA and KY community samples was responsible for the state of residence effect in the MANOVA using the non-revised "respect" ratings. Recall that CA elders were more educated than KY elders, and were therefore more likely to understand the meaning of "controlling" and "patronizing," which were the two commonly misunderstood ratings averaged with "respect" to create the original dependent variable of "respect." Once those ratings were removed, the state of residence effect was no longer significant.

Given that the CA and KY samples did not vary systematically on the dependent variables, the primary analysis comparing nursing home to community elders was examined. In order to test the first hypothesis that, in comparing the ratings of neutral and patronizing speech, community-dwellers would rate patronizing speech style more negatively than the institution-dwellers, a 2 (speech style) X 2 (actress pair) X 2 (speech style order) X 2 (respondents' place of dwelling) repeated-measures MANOVA was calculated. Speech style served as the repeated-measure, and this analysis included the five dependent variables associated with evaluative perceptions of speech style. An interaction between speech style and respondents' residence would be required to support 
the hypothesis; such an effect was not found. As in the community sample alone, there was a main effect for speech style, $\underline{F}(5,88)=12.58, \mathrm{p}<.05$.

A speech style by speech style order interaction, $\underline{F}(5,88)=2.72, \mathrm{p}<.05$, also emerged. Univariate analyses, shown in Table 4, revealed significant differences for speech style on all five dependent variables. The significant effect for speech style provides

Table 4

Speech Style Main Effects from the MANOVA Comparing Speech Style Ratings of Nursing Home and Community Elders.

\section{Speech Style}

Patronizing

Neutral

Dependent Variables

$\underline{\mathbf{M}} \quad \underline{\mathrm{SD}}$

M $\quad \underline{\text { SD }}$

F $(1,92)$

Nurse

$\begin{array}{llllll}\text { Respect } & 3.92 & 1.37 & 5.43 & 1.37 & 38.89^{*} \\ \text { Nurturance } & 5.34 & 1.43 & 6.08 & 0.98 & 15.01^{*} \\ \text { Benevolence } & 5.76 & 1.11 & 6.31 & 0.77 & 14.88^{*} \\ \text { Competence } & 6.04 & 1.16 & 6.49 & 0.75 & 6.77^{*}\end{array}$

Elder

Satisfaction

$5.01 \quad 1.54$

6.40

0.89

$52.24^{*}$

${ }^{*} \mathrm{p}<.05$. 
evidence that the manipulation of speech styles in the vignettes was successful. Elderly respondents, regardless of whether they live in a nursing home or community setting, evaluated the nurse using neutral speech more favorably than the nurse using patronizing speech, and the elder target was seen as more satisfied with the neutral speech versus the patronizing speech.

Univariate analyses determined one significant speech style X speech style order interaction for ratings of the nurse's nurturing qualities, $E(1,92)=5.03, p<.05$. When patronizing speech was shown in the second vignette the nurse using it was downgraded more on nurturance than when the patronizing vignette was shown first. An illustration of this interaction, as well as the means and standard deviations for the nurturance ratings may be found in Figure 2. The same analyses were computed using the revised "respect" ratings. The results found above did not change with this analysis.

It is possible that the community and nursing home elders had different perceptions regarding how well the nurse and elder knew each other, and that those differences influenced evaluations of the different speech styles. Ratings were taken following the presentation of each vignette on how well the nurse and elder target knew each other ( 1 = "not all" through 7 = "very, very much"). A 2 (speech style) X 2 (respondent's place of dwelling) repeated-measures ANOVA determined a significant main effect for speech style such that the elder and nurse were thought to have known each other better in the neutral vignettes than the patronizing vignettes, $F(1,98)=12.65$, $\mathrm{p}<.05$. However, no significant effect was found for respondent's place of dwelling [F $(1,98)=1.54, p>.05]$, nor was there a significant interaction between speech style and 


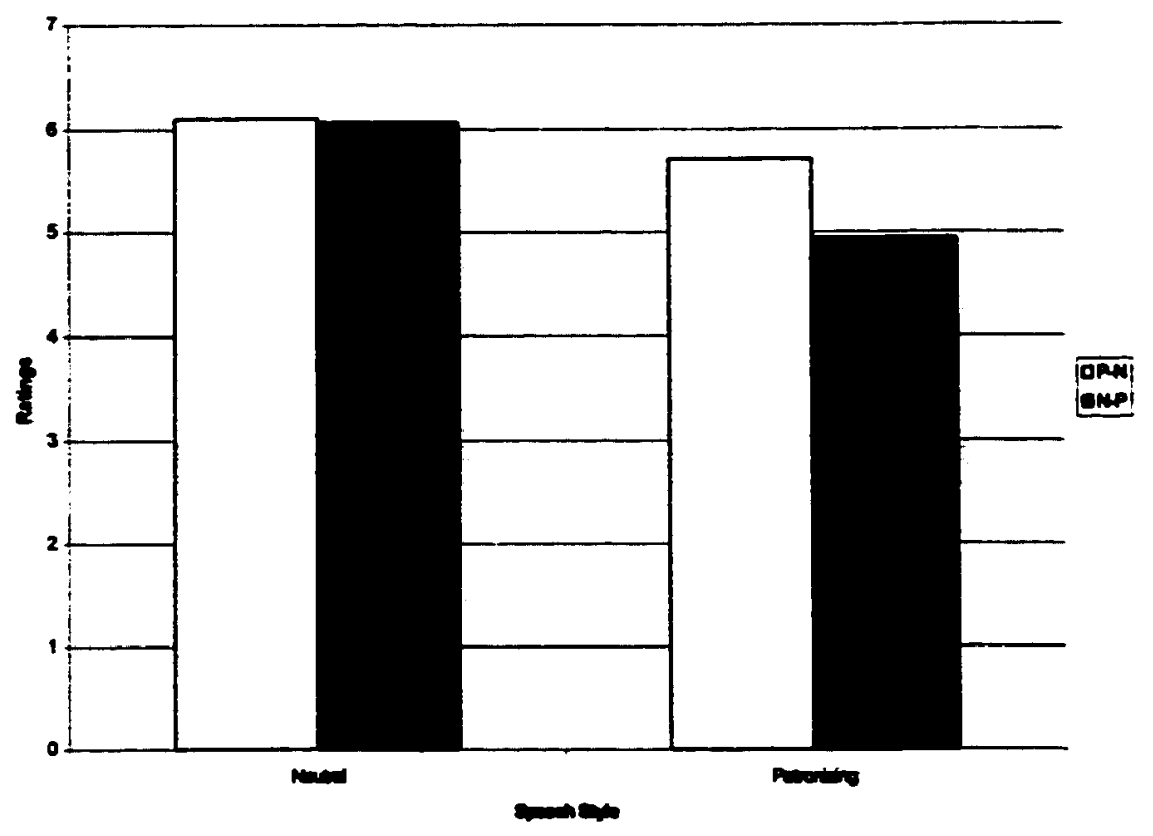

Figure 2

Ratings of Nurse's Nurturance in the Patronizing and Neutral Vignettes by the Order in which the Vignettes Were Shown.

Note: $\mathrm{N}-\mathrm{P}$ indicates that the patronizing vignette was viewed second, and $\mathrm{P}-\mathrm{N}$ indicates that the patronizing vignette was viewed first. The interaction illustrates that when the patronizing vignette is shown second (N-P) as opposed to first $(P-N)$, the nurturance ratings for the patronizing vignette are much lower than they are for the neutral vignette. Mean nurturance ratings in the patronizing vignette were $5.71(\underline{S D}=1.22)$ when patronizing vignette was viewed first and $4.94(S D=1.55)$ when it was second. In the neutral vignette, mean nurturance ratings were $6.10(S \mathrm{SD}=0.88)$ when patronizing preceded neutral, and 6.06 $(\mathrm{SD}=1.09)$ when neutral preceded patronizing. 
respondent's place of dwelling $[\mathrm{F}(1,98)=0.88, \mathrm{p}>.05]$. The means and standard deviations from this analysis are shown in Table 5.

Table 5

Community and Nursing Home Respondents' Perceptions of How Well the Nurse and Elder Target Knew Each Other in the Patronizing and Neutral Vignettes.

\section{Vignette}

\begin{tabular}{rccccc} 
& \multicolumn{2}{c}{ Patronizing } & \multicolumn{2}{l}{ Neutral } \\
Respondents & $\underline{M}$ & $\underline{\text { SD }}$ & $\underline{M}$ & $\underline{\text { SD }}$ \\
\hline Community & 2.77 & 1.87 & 3.68 & 1.92 \\
Nursing Home & 3.40 & 1.88 & 3.92 & 2.19 \\
\multicolumn{1}{c}{ Total } & 3.01 & 1.89 & 3.77 & 2.02 \\
\hline
\end{tabular}

Effects of Length of Institutionalization and Cognitive Ability in Nursing Home Sample

The second hypothesis, that the longer the elder has resided within an institution the less negatively she will evaluate patronizing speech in comparison to neutral speech, and the fifth hypothesis, that cognitive ability will account for a significant proportion of variance in speech ratings, were initially examined with a repeated-measures MANCOVA. This analysis included only the nursing home sample, speech style was the repeated-measure, and SPMSQ scores (cognitive ability) and months of institutionalization were the covariates. 
The MANCOVA did not determine any significant effect for length of institutionalization $[F(5,31)=0.26, p>.05]$, failing to support the second hypothesis. However it did reveal main effects for speech style $[E(5,31)=4.72, \mathrm{p}<.05]$ and cognitive ability $[\mathrm{F}(5,31)=3.58, \mathrm{p}<.05]$, and an interaction between cognitive ability and speech style $[\mathrm{F}(5,31)=2.79, \mathrm{p}<.05]$, providing support for the fifth hypothesis. Univariate tests for speech style, again, show that neutral speech is preferred over patronizing speech on all five dependent variables (see Table 6). Cognitive ability was shown to have a significant relationship with ratings of the nurse's perceived competence $[E(1,35)=7.98$, p <.05]. A bivariate correlation was calculated to determine the nature of the relationship between cognitive ability and the average of the neutral and patronizing competence ratings. It was determined that the higher the respondent's cognitive ability the more positively she rated the nurse's competence in general (Pearson $\underline{r}=0.42, \underline{p}<.05$ ).

The cognitive ability by speech style interaction was significant for the ratings of "respect," $\mathrm{F}(1,35)=7.98, \mathrm{p}<.05$. To determine the nature of this interaction bivariate correlations were calculated between cognitive ability and the respect ratings for both the neutral and patronizing vignettes. A significant positive relationship was determined between cognitive ability and neutral ratings of respect, revealing that as cognitive ability increases, the more respectful nurses using neutral speech are rated (Pearson $\underline{\underline{r}}=0.42, \mathrm{p}<$ .05). However, cognitive ability was not related to ratings of respect for the nurse in the patronizing vignette, Pearson $\underline{r}=-0.05, p>.05$. That is, cognitive ability was related to perceptions of respect only under the neutral speech condition, and not under the patronizing condition. 
Table 6

Speech Style Main Effects from the MANCOVA on Nursing Home Older Adults

Examining the Effects of Speech Style, Lenoth of Institutionalization, and Cognitive

Ability.

\section{Speech Style}

Patronizing Neutral

$\begin{array}{llllll}\text { Dependent Variables } & \underline{M} & \underline{\text { SD }} & \underline{\mathrm{M}} & \underline{\mathrm{SD}} & \underline{F}(1,35)\end{array}$

Nurse

$\begin{array}{lccccc}\text { Respect } & 4.18 & 1.25 & 5.47 & 1.37 & 18.47^{*} \\ \text { Nurturance } & 5.55 & 1.30 & 6.25 & 0.72 & 9.36^{*} \\ \text { Benevolence } & 5.89 & 0.98 & 6.33 & 0.67 & 7.80^{*} \\ \text { Competence } & 5.99 & 1.02 & 6.50 & 0.78 & 7.02 *\end{array}$

Elder
Satisfaction
$5.13 \quad 1.58$
6.43
0.72
20.09*

${ }^{*} \mathrm{p}<.05$.

The MANCOVA examining the revised respect ratings found similar effects for style of speech and cognitive ability, however, it did not find the cognitive ability by speech style interaction to be significant. If elders with lower cognitive ability were more likely to misunderstand the "controlling" and "patronizing" ratings that compose part of the overall "respect" variable, it is possible that they may have rated these in an 
inconsistent direction, thereby masking a potentially negative relationship between cognitive ability and ratings of respect in the patronizing condition. To determine if this was the reason behind the disappearance of interaction in the analysis using the revised "respect" ratings, bivariate correlations were calculated between cognitive ability and each of the revised "respect" ratings (i.e. patronizing and neutral). The resulting correlations were nonsignificant: cognitive ability was not related to ratings of respect in either the neutral (Pearson $I=0.24, p>.05)$ or patronizing (Pearson $\underline{I}=-0.20, p>.05$ ) conditions. This finding is puzzling, and suggests that the confusion caused by misinterpreting these ratings was not straightforward.

Because cognitive ability was found to be a significant predictor of speech ratings, as was speech style and the speech style by cognitive ability interaction (in the primary analysis), the next step was to determine whether or not speech style predicted any unique variance in speech ratings beyond that of cognitive ability and length of institutionalization. Although length of institutionalization was not found to be significant in the MANCOVA, it was included in this analysis as to exclude it would be the equivalent of accepting the null that this variable had no effect. Ten multiple regression analyses were performed with the patronizing and neutral ratings on each of the five rating scales as dependent variables, and cognitive ability and length of institutionalization as predictor variables. A summary of the results from these analyses is shown in Table 7. The standardized residuals for speech style were then analyzed in a repeated-measures MANOVA. The results indicate that speech style does not account for a significant portion of unique variance beyond the variance accounted for by the other 
Table 7

Results from the Regression Analyses Examining Effects of Cognitive Ability and Lenoth of Institutionalization on Ratings of Speech Styles within the Nursing Home Sample.

\begin{tabular}{cccccccc}
\hline & \multicolumn{2}{c}{ Regression } & \multicolumn{2}{c}{ Cognitive Ability } & \multicolumn{2}{c}{ Months in Institution } \\
Dependent Variables & $\underline{\mathrm{F}}$ & $\underline{\mathrm{R}}^{2}$ & $\beta$ & $\underline{\mathrm{t}}$ & $\beta$ & $\underline{\mathbf{t}}$ \\
\hline Respect & & & & & & \\
Patronizing & 0.33 & 0.02 & -0.07 & -0.40 & -0.13 & -0.75 \\
Neutral & $4.22^{*}$ & 0.19 & 0.44 & $2.88^{*}$ & 0.12 & 0.79
\end{tabular}

Nurturance

$\begin{array}{lcccccc}\text { Patronizing } & 1.23 & 0.07 & -0.25 & -1.50 & -0.11 & -0.68 \\ \text { Neutral } & 0.76 & 0.04 & 0.15 & 0.89 & 0.17 & 0.99\end{array}$

Benevolence

$\begin{array}{lcccccc}\text { Patronizing } & 0.55 & 0.03 & -0.15 & -0.89 & -0.12 & -0.70 \\ \text { Neutral } & 1.17 & 0.06 & 0.25 & 1.51 & 0.09 & 0.52\end{array}$

Nurse's Competence

$\begin{array}{lllllll}\text { Patronizing } & 0.59 & 0.03 & 0.18 & 1.08 & 0.03 & 0.19 \\ \text { Neutral } & 6.58^{*} & 0.27 & 0.53 & 3.61^{*} & 0.14 & 0.97\end{array}$

Elder Target's Satisfaction

\begin{tabular}{ccccccc} 
Patronizing & 0.17 & 0.01 & 0.09 & 0.54 & -0.02 & -0.12 \\
Neutral & 1.55 & 0.08 & 0.16 & 0.97 & 0.26 & 1.60 \\
\hline${ }^{*} \mathrm{p}<.05$. & & & & & &
\end{tabular}


predictors, $\underline{F}(5,37)=0.19, \mathrm{p}>.05$. Similar results were found in the MANOVA using the revised "respect" rating residuals.

Note in Table 7 the significant positive relationships between cognitive ability and ratings of the nurse's respect $(t=2.88, \mathrm{p}<.05)$ and competence $(t=3.61, \mathrm{p}<.05)$ in the neutral condition (see Table 7). This suggests that cognitive ability is a significant predictor of ratings of neutral speech. However, cognitive ability was not a significant predictor of ratings in the patronizing conditions. This counters the rationale for the fifth hypothesis that elders higher in cognitive ability would be more likely downgrade patronizing speech as opposed to neutral speech. Concluding from these results, patronizing speech is not necessarily downgraded as cognitive ability of the respondent increases, but neutral speech is especially preferred as cognitive ability rises. Evidently, the differential predictive power of cognitive ability on neutral and patronizing speech ratings for nurse's competence was not strong enough to produce a significant interaction for this dependent variable in the overall MANCOVA. Rather, cognitive ability was revealed only as a significant main effect for this variable.

\section{Effect of Cognitive Ability in the Community Sample}

Similar to the analysis performed on the nursing home sample in the previous section, a MANCOVA was calculated to determine the effect of cognitive ability on community elders' perceptions of speech style. As in prior analysis, a main effect for style of speech was significant, $\underline{F}(5,56)=11.38, p<.05$, and univariate tests showed that it was significant for all five dependent variables. 
A main effect for cognitive ability was also revealed $[\mathrm{E}(5,56)=2.64, \mathrm{p}<.05]$ with univariate tests determining a significant effect for "nurse's competence" $[\mathrm{F}(1,60)=$ $9.33, \mathrm{p}<.05]$ and "benevolence" $[\mathrm{F}(1,60)=10.03, \mathrm{p}<.05]$. To determine the direction of the effect, the patronizing and neutral ratings were averaged for both "nurse's competence" and "benevolence." Then, bivariate correlations were calculated with each of these variables and cognitive ability. These analyses indicated that as respondents' cognitive ability increased, the more favorably they rated the nurse's competence (Pearson $\underline{\underline{r}}=0.37, \underline{\mathrm{p}}<.05)$ and benevolence (Pearson $\underline{\mathrm{r}}=0.38, \mathrm{p}<.05)$. Similar effects for speech style and cognitive ability emerged in the MANCOVA using the revised "respect" ratings.

Again, multiple regression analyses were calculated for the dependent variables on each level of speech style using cognitive ability as the covariate (see Table 8). The residuals were then analyzed in a repeated-measures MANOVA to determine if style of speech was still significant once the variance accounted for by cognitive ability was removed. As was found in the nursing home sample, style of speech was no longer a significant predictor of community elders' speech ratings beyond what was predicted by cognitive ability, $\underline{F}(5,109)=0.32, \mathrm{p}>.05$. In the MANOVA examining the revised "respect" residuals, similar results were found.

Similar to the results found in the nursing home sample, cognitive ability showed a positive relationship to ratings of sperch style. Both the nurse's benevolence $(t=3.06, p$ $<.05)$ and the elder target's satisfaction $(t=2.13, p<.05)$ were rated more favorably in the neutral condition as the respondents' cognitive ability increased. However, unlike the 
Table 8

Results from the Regression Analyses Examining Effects of Cognitive Ability on Ratings

of Speech Styles within the Community Sample.

\begin{tabular}{ccccc}
\hline & \multicolumn{2}{c}{ Regression } & \multicolumn{2}{c}{ Cognitive Ability } \\
Dependent Variables & $\underline{F}$ & $\underline{\mathbf{R}}^{2}$ & $\beta$ & $\underline{\mathbf{t}}$ \\
\hline Respect & & & & \\
Patronizing & 0.00 & 0.00 & 0.00 & 0.01 \\
Neutral & 3.55 & 0.06 & 0.24 & 1.88
\end{tabular}

Nurturance

$\begin{array}{lllll}\text { Patronizing } & 0.46 & 0.01 & 0.09 & 0.68 \\ \text { Neutral } & 2.28 & 0.04 & 0.19 & 1.51\end{array}$

Benevolence

$\begin{array}{lllll}\text { Patronizing } & 3.56 & 0.06 & 0.24 & 1.89 \\ \text { Neutral } & 9.35^{*} & 0.14 & 0.37 & 3.06^{*}\end{array}$

Nursc's Competence

$\begin{array}{lllll}\text { Patronizing } & 4.90^{*} & 0.08 & 0.28 & 2.21^{*} \\ \text { Neutral } & 6.05^{*} & 0.09 & 0.30 & 2.46^{*}\end{array}$

Elder Target's Satisfaction

\begin{tabular}{ccccc} 
Patronizing & 0.91 & 0.02 & 0.12 & 0.95 \\
Neutral & $4.54^{*}$ & 0.07 & 0.27 & $2.13^{*}$ \\
\hline $\mathrm{p}<.05$. & & & & \\
\hline
\end{tabular}


results found in the nursing home sample, increased cognitive ability predicted more favorable ratings of the nurse's competence in both the neutral $(t=2.21, p<.05)$ and patronizing $(t=2.46, \mathrm{D}<.05)$ conditions. From these results, it appears that, in general, cognitive ability tends to predict neutral speech ratings more so than patronizing. Nevertheless, no interaction term emerged in the overall MANCOVA, which is likely due to the fact that cognitive ability predicts both patronizing and neutral speech styles on the dependent variable of nurse's competence within this sample.

\section{Effect of Target Elder's Place of Dwelling}

The next analysis determined the effects of the elder target's place of dwelling (nursing home versus community) on ratings of patronizing speech (hypothesis 3 ) and perceptions of the elder target's competence and activity/potency (hypothesis 4). A 2 (speech style) X 2 (actress pair) X 2 (speech style order ) X 2 (elder target's place of dwelling) repeatedmeasures MANOVA was calculated with speech style as the repeated-measure. This analysis included all five dependent variables associated with evaluative perceptions of speech style (to test hypothesis 3), as well as the dependent variables of "elder target's activity/potency" and "elder target's competence" (to test hypothesis 4).

Specifically, an interaction between speech style and the elder target's place of dwelling was predicted in which patronizing speech would be rated less favorably than neutral speech, particularly when the elder target resided in a community setting versus an institutional setting. A similar interaction was expected for ratings of the target elder such that a patronized institutionalized elder would be downgraded more than a . patronized community elder target in terms of activity/potency and competence. The 
results of the MANOVA yielded an overall effect for style of $\operatorname{speech}[F(7,48)=8.75, \mathfrak{D}<$ $.05]$. Elder targets who received patronizing speech were downgraded more on competence and activity/potency ratings than elders receiving neutral speech, regardless of whether the elder target lived in the community or nursing home setting (see Table 9). This suggests an overall "blaming the victim" effect that is not tempered even when the elder target resides in a community setting.

Table 9

Speech Style Effects from the MANOVA Comparing Community Elders' Perceptions of Speech Styles Based on the Elder Target's Place of Dwelling.

\begin{tabular}{|c|c|c|c|c|c|}
\hline \multirow[b]{3}{*}{ Dependent Variables } & \multicolumn{4}{|c|}{ Speech Style } & \multirow[b]{3}{*}{$E(1,54)$} \\
\hline & \multicolumn{2}{|c|}{ Patronizing } & \multicolumn{2}{|c|}{ Neutral } & \\
\hline & $\underline{\mathbf{M}}$ & $\underline{\mathrm{SD}}$ & $\underline{\mathbf{M}}$ & $\underline{\mathrm{SD}}$ & \\
\hline \multicolumn{6}{|l|}{$\overline{\text { Elder }}$} \\
\hline Competence & 5.64 & 1.32 & 6.23 & 0.99 & $13.59 *$ \\
\hline Activity/Potency & 5.56 & 1.09 & 6.08 & 0.89 & $12.02 *$ \\
\hline
\end{tabular}

As was proposed in the additional analyses for the first hypothesis, it is possible that the lack of interactions predicted by the third and fourth hypotheses was due to differences in the community respondents' perceptions of how well the nurse and target elders knew each other. Therefore, a 2 (speech style) X 2 (target elder's place of 
dwelling) repeated-measures ANOVA was calculated. A significant effect for speech style was found such that dyads in the neutral vignettes were perceived to know each other better than those in the patronizing vignettes, $\mathrm{F}(1,60)=11.42, \mathrm{p}<.05$. However, no significant effect for target elder's residence was found $[F(1,60)=0.001, p>.05]$, nor was there a significant interaction $[F(1,60)=0.08, p>.05]$. Means and standard deviations from this analysis are shown in Table 10.

Table 10

The Effects of Speech Style and Target Elder's Residence on Community Respondents' Perceptions of How Well the Nurse and Elder Target Knew Each Other.

\section{Vignette}

Patronizing Neutral

Target Elders $\quad \underline{M} \quad \underline{\text { SD }} \quad \underline{M} \quad \underline{\text { SD }}$

\begin{tabular}{rllll}
\hline Community & 2.74 & 1.88 & 3.71 & 1.99 \\
Nursing Home & 2.82 & 1.89 & 3.64 & 1.87 \\
Total & 3.71 & 1.99 & 3.68 & 1.92 \\
\hline
\end{tabular}

Again, because the speech style effect was consistent across groups, the lack of interactions predicted by the third and fourth hypotheses was not likely due to differences in how well the nurses and elder targets were perceived to know each other. In sum, when nurses spoke to elder targets with a more neutral style of speech (versus patronizing), the 
nurse was evaluated more favorably, the elder target was perceived to be more satisfied, competent, and active/potent, and the dyad was believed to have known each other better. 


\section{DISCUSSION}

\section{Preference for Neutral Speech}

The most consistent finding throughout all analyses in this study was that community and nursing home elders prefer neutral speech to patronizing speech. This effect was significant across all dependent variables, such that, in comparison to the nurses in the patronizing vignette, respondents rated the nurses in the neutral vignette as more respectful, nurturing, competent, and benevolent, and the elder targets of neutral speech as more satisfied with the conversation. These results support the findings of Whitbourne et al. (1995) that both institutionalized and community-dwelling elderly adults prefer adult speech to patronizing speech. Additionally, this preference for neutral speech confirms the Communication Predicament Model of Aging in that overaccommodating speech is evaluated negatively by elderly adults.

However, community-dwelling elders did not find patronizing speech (versus neutral speech) less preferable than did institutionalized elders, thus failing to support the first hypothesis of this study. These results contrast the findings of past studies including a) Ryan and Cole (1991) who determined that nursing home residents were more likely than community elders to perceive baby talk as nurturing; b) Whitbourne et al. (1995) who found that community-dwelling elders showed a greater preference than institutionalized elders for adult speech over patronizing speech; and c) Caporeal (1983) who found a negative correlation between elders' functional ability and their preference 
for baby talk. From past research it would seem that a more simplified and overaccommodating style of speech would more likely be tolerated by respondents in institutional settings or settings in which elders require more care than it would by community-dwelling elders. However, the results of this study do not support that supposition. Rather, this study suggests that patronizing speech is generally inappropriate for all elders.

Interestingly, there was an interaction between the order in which the speech styles were presented and how negatively patronizing speech was evaluated in comparison to neutral speech. Although this effect was only significant for ratings of the nurse's nurturance, when patronizing speech was viewed second, the nurse was given poorer ratings of nurturance than when it was viewed first. It appears that in this case, once the respondents had experienced the nurse in the neutral context, the patronizing context seemed even worse than it did when it was seen prior to the neutral vignette.

Additionally, it was considered that the absence of the predicted interaction effect may have been the result of group differences in how well the nurse-elder dyads were assumed to have known each other. Although there were no group differences, there was a significant effect for speech style such that dyads in the neutral vignette were assumed to know each other better than those in the patronizing vignette. The fact that dyads in the neutral context were believed to know each other better than the dyads in the patronizing context is counter-intuitive since patronizing speech tends to possess an overly-familiar tone. Interestingly, not only did neutral speech result in higher ratings of the nurse's respectfulness, competence, nurturance, and benevolence, and increased ratings of the 
elder target's satisfaction, but it also resulted in the perception that the interlocutors were more familiar with each other.

\section{Absence of Effect for Length of Institutionalization}

The second hypothesis, that length of institutionalization would significantly predict differences in perceptions of patronizing speech, was not supported. Given the past literature on the process of adapting to institutional life upon entering a nursing home, it was expected that as length of institutionalization increases, the more tolerant elders would become of patronizing speech. Brooke (1989) posited that there are four phases of adjustment with the initial period of adjustment taking two months, and the entire adjustment lasting roughly six months. Although the current study recruited elderly adults who had been institutionalized for at least two months, elders that had been in nursing homes during the time period of greatest adjustment (i.e. between two and six months) accounted for only $21.1 \%$ of the institutionalized sample. Given that the greatest variability in ratings would most likely be found during this period, there may not have been enough respondents undergoing this critical time of the adjustment process for there to be an effect for length of institutionalization.

Because this study is the first to look at length of institutionalization more research is needed in this area. Future studies might restrict the institutionalized sample to elders who have only been in nursing homes for six months, thereby potentially capturing the greatest variability in speech ratings, assuming that length of institutionalization is a significant factor in perceptions of speech style. Nevertheless, given the fact that most of the nursing home sample had been institutionalized well beyond the adaptation period 
and still preferred neutral speech to patronizing speech, whether or not length of institutionalization is a factor seems somewhat inconsequential.

\section{Effects of Cognitive Ability}

Cognitive ability was shown to be a significant factor in speech style ratings for both the institutionalized and community-dwelling samples, supporting this study's fifth hypothesis. Among institutionalized elders the higher the respondents' cognitive ability, the more positively the nurse's competence was rated. In the multiple regression analyses performed on both the patronizing and neutral ratings of speech style with cognitive ability and length of institutionalization as predictors, cognitive ability showed a significant positive relationship with ratings of the nurse's competence, but only in the neutral condition. While there was a significant relationship between cognitive ability and ratings of the nurse's respect (in the neutral context) the effect was not interpretable as it was not significant when using the revised "respect" ratings.

Although cognitive ability only predicted ratings of competence in the neutral context (in this sample), the differential effect was not strong enough to emerge as a cognitive ability by speech style interaction for nurse's competence in the overall multivariate analysis. When factoring out the effects of cognitive ability and length of institutionalization within the nursing home sample, no significant differences were found in ratings of patronizing speech versus neutral speech. This suggests that differences in speech style ratings are largely accounted for by variations in cognitive ability.

Cognitive ability was also found to be significant predictor of speech ratings in the community sample. In this case, though, cognitive ability showed a positive 
relationship to both the nurse's competence and benevolence ratings. Multiple regression analyses on patronizing and neutral ratings of speech with cognitive ability as the predictor determined that cognitive ability positively correlated with the neutral ratings of the nurse's benevolence and the elder target's satisfaction, and with both neutral and patronizing ratings of the nurse's competence. Again, even though cognitive ability differentially predicted neutral versus patronizing speech ratings on the benevolence and satisfaction variables, the effect was not strong enough to emerge as an interaction in the overall multivariate analysis. This was likely due to the fact that cognitive ability showed a strong positive relationship with both neutral and patronizing ratings of the nurse's competence, attenuating any overall interaction effects. As was found in the nursing home sample, once removing the variance accounted for by cognitive ability, the speech style effect was no longer significant.

Interestingly, although the fifth hypothesis was supported by these results, cognitive ability consistently predicted positive ratings of speech and, most often, in the neutral context. Past research has been fairly inconsistent as to what the effects of cognitive ability are in perceptions of patronizing speech, particularly because the cognitive ability of the respondent has rarely been examined. The one study that did take cognitive ability into account compared the perceptions of nursing home respondents with dementia versus those without dementia (Sachweh, 1998). In that study, the residents with dementia were most likely to demonstrate both approval and disapproval of baby talk, a result that did not necessarily provide a conclusive direction for the effect. 
It has been predicted in past studies that it would be more appropriate to patronize confused elders versus cognitively alert elders (Giles et al., 1993; Ryan et al., 1991; Ryan, Meredith, et al., 1994, Ryan et al., 1995). However, this hypothesis was confirmed in only one study (Ryan et al., 1995), and, in fact, the opposite effect was found by Giles et al. (1993) in that nurses using neutral speech toward confused residents were rated as more nurturant and less helpless than nurses using patronizing speech toward those residents. The current study is one of the few that has actually measured cognitive ability directly and examine its effect as a covariate in respondents' evaluations of speech styles. Cognitive ability was related to more favorable ratings of neutral speech in both the community and institutionalized samples. This suggests that it is not necessarily more acceptable to patronize confused elders, but that the more cognitively competent elders are, the more positively they respond to neutral speech. Because there are so few studies that have directly measured cognitive ability and its effect in this study is unique, further research is needed to clarify this variable's influence in evaluations of speech styles.

\section{Effects of Speech Style on Community Respondents' Perceptions of the Elder Target}

As mentioned previously, community respondents showed a preference for neutral speech over patronizing speech. Additionally, the elder target of patronizing speech was rated as less satisfied with the conversation, less competent, and less active/potent. The fact that the elder target of patronizing speech was downgraded more than the elder target of neutral speech is evidence for a "blaming the victim" effect. Blaming the victim was one explanation for past studies which have demonstrated that younger adults tend to rate patronizing speech more negatively than do older adults (Edwards \& Noller, 1993; Ryan, 
Hamilton, et al., 1994). That is, older adults may have rated patronizing speech less negatively because they perceived the elder recipient as communicatively deficient, hence requiring speech accommodation. This proposition was supported by Giles et al. (1993) who found that older adults perceived patronized elders as less competent than did younger adults.

However, other studies examining elderly respondents' perceptions of the patronized elder target's competence have not demonstrated blaming the victim (Ryan, Hamilton, et al., 1994; Hummert \& Gartska, 1996). The current study illustrates the negative consequences for the recipient of patronizing speech, which supports the Communication Predicament Model of Aging. The model predicts that patronizing speech occurs as a result of negative stereotyping, and that a cooperative response by the elderly target of patronizing speech confirms those negative evaluations. The elderly targets in this study's vignettes responded cooperatively regardless of the type of speech style directed toward them, and, indeed, they were evaluated as less competent and active/potent when spoken to in a patronizing tone.

One of the alternative explanations for the different perceptions of younger and older adults in prior studies was that community-dwelling elders might be more likely than young adults to distinguish patronizing speech as being accommodative to institutionalized elders, as opposed to being overaccommodative. However, the manipulation of the target elder's place of residence did not result in differential perceptions of speech style or elder target's competence and activity/potency. 
These findings are somewhat consistent with Stewart and Ryan (1982) and Hummert et al. (1998) who found that it is easier to elicit and maintain negative stereotypes than it is to change them with positive conflicting information. Hummert et al. (1998) determined that placing negatively-stereotyped elders in a community context did little to attenuate the respondents' tendency to overaccommodate their speech toward those elders. However, when positively-stereotyped elders were placed in a hospital context, the respondents believed that they would be more likely to overaccommodate than if the elders had been in a community context. Similarly, Stewart and Ryan (1982) found that slower speaking individuals were judged to be older than they were, and that, although faster speech did little to raise evaluations of elderly adults, it significantly raised evaluations of younger adults.

The results do not, however, support the third and fourth hypotheses of this study, predicting that the nurse and target elder would be downgraded more in the patronizing context versus neutral when the elder target was said to live in the community as opposed to a nursing home, as predicted by the Communication Predicament Model of Aging. The model would predict that the stronger the aging cues: a) the more likely negative stereotyping would occur; b) the less inappropriate patronizing speech would be perceived to be; and c) the less competent and active/potent the elder target of patronizing speech would be perceived to be.

Unfortunately, the manipulation of the elder target's place of dwelling was not likely strong enough to produce the predicted effect. Evidence for this was revealed in the respondents' comments about their ratings. Rarely did the respondents give ratings 
without some commentary or rationale for their opinions and perceptions. In fact, this was how the interviewers knew whether or not they understood the rating system; that is, when their comments were incongruent with their ratings, this would prompt the interviewer to query and correct any misunderstandings in the task. Surprisingly, not one of the respondents ever commented about the setting in which the interaction took place, even though the setting was mentioned before viewing each vignette.

Most likely, the vignette setting was not salient enough when it was said to be a nursing home. Recall that the same vignettes were used for each setting, such that the only manipulation for setting was the interviewer informing the respondent where the interaction was taking place. To increase the believability of the nursing home setting, it was arranged such that the nurses always helped the elder targets up from their chairs before taking them back to get the flu shot. However, nursing home elders are typically not as independently ambulatory as the elderly actresses in the vignettes. Additionally, due to lack of monetary resources, professional actresses and staging could not be afforded. Both elderly women in the vignettes wore slacks, blouses, and a blazer or sweater which, when the vignette was said to take place in a nursing home, was not likely to be believable. Similarly, the staging of the vignettes included the lobby of a university psychology clinic and the corner of a church sanctuary made up to look like a lobby of a nurse's office/station. Between the staging and costumes the setting looked more like a community health care center than a nurses' station in a nursing home. These cues were likely more salient than the verbal cues provided by the interviewers, thereby failing to elicit negative stereotyping as a result of the setting manipulation. 
In future studies, successful manipulation of the setting will likely require actresses that are actual nurses and elders from both community ard nursing home settings. Obviously, securing these resources was beyond the budget of this study, but may be required if videotaped vignettes are to be used as stimuli. The inclusion of additional cues that accompany both of these settings would also be helpful. For example, the sounding of call buttons, residents in wheelchairs, and other nurses coming to and from the station would increase the salience of the nursing home setting.

\section{Future Directions}

A logical next step to the current study would be to compare caregiver and care receiver evaluations of patronizing speech, much like the Edwards and Noller (1993) study comparing nursing students, psychology students, and elderly adults. Using the videotaped vignettes from this study, nursing students and nurses working in both community and institutional settings could be interviewed, and their opinions of different speech styles recorded. By determining if and how perceptions differ among these nursing groups and the elderly groups from this study, steps toward training caregiving professionals in effective intergenerational communication may be implemented. The development of a comprehensive training program on how to increase the quality of intergenerational communication would be beneficial to all helping professions that commonly provide care to elderly adults including the medical, psychological, and nursing professions.

The task of developing a training program would also be aided by operationalizing what constitutes patronizing speech and overaccommodation. 
Throughout the literature, patronizing speech and intergroup overaccommodation has been defined in a variety of ways, which makes comparing results and draving conclusions difficult. Definitions range from specific linguistic terms such as number of words per utterance (Ashburn \& Gordon, 1981) to exaggerated intonation and highpitched speech (Caporeal et al., 1983) to all actions and communications used to foster dependency in elderly adults (Dolinsky, 1984). One reason that this speech style is so difficult to operationalize is that the design of any given study dictates and limits what kinds of stimuli can be used to portray patronizing speech and what kinds of criteria constitute patronization in naturally occurring speech.

An additional problem is that communication is composed of vocal aspects, linguistic aspects, and nonverbal aspects (Ryan et al., 1986), which are often difficult to isolate. Future studies examining the specific aspects of verbal and nonverbal communication that cause patronizing speech to be perceived as such will facilitate its operationalization. An example of such a study is Edwards and Noller (1993) who examined perceptions of several variations of patronization including a touch to the shoulder alone, expression of endearment alone, high pitch alone, and paired combinations of the three.

Finally, cultural, ethnic, and gender differences may play a strong role in determining what distinguishes speech as accommodative and friendly from what is overaccommodative and intrusive. For example, forms of address vary from region to region in the United States, and their appropriateness is dependent upon where they are used. A weakness of the current study is that perceptions of patronizing speech were 
limited to interactions between Caucasian women. Future research may examine not only intergenerational communication but also explore the influence of opposite sex dyads and interracial dyads on perceptions of speech style.

\section{$\underline{\text { Conclusions }}$}

Across both community-dwelling and nursing home elders, patronizing speech was evaluated less favorably than neutral speech. Contrary to what was predicted, community elders did not rate patronizing speech (versus neutral) more negatively than the nursing home elders, suggesting that overaccommodation is no more likely to be tolerated by institutionalized older adults than it is by community-dwelling elders. When the patronizing vignette was viewed following the neutral vignette (as opposed to before), the patronizing nurse was perceived to be less nurturant by respondents in general, indicating that once experiencing the neutral context, the patronizing context was perceived as all the more distasteful. Additionally, nurse-elder dyads were assumed to know each other better when the nurse in the vignette spoke in a neutral tone toward the elder target rather in a patronizing tone.

Also contrary to what was predicted, length of institutionalization was not a significant factor in nursing home respondents' evaluations of speech styles. It is possible that the absence of this effect was due to the fact that there were too few elders in the sample that had been institutionalized between two and six months, a time period associated with greatest adaptation to the institutional environment (Brooke, 1989). Nonetheless, there was a significant speech style effect within this sample, suggesting 
that, regardless of how long the elders had been institutionalized, they still preferred neutral to patronizing speech.

As predicted by this study, cognitive ability was a significant influence in both the community and nursing home samples' perceptions of speech styles. Furthermore, once accounting for the effects of cognitive ability (and length of institutionalization in the nursing home sample), the effect for speech style was no longer significant. The specific influence of cognitive ability was somewhat of a surprise in that increasing levels of cognitive ability typically predicted more positive ratings of neutral speech in both samples, but not negative ratings of patronizing speech. Given this unique finding, further exploration of this variable will be required, particularly since there is a lack of studies examining respondents' cognitive ability as a covariate in perceptions of speech styles.

Community-dwelling elderly adults found patronizing speech to be less preferable than neutral speech. However, patronizing speech was not perceived to be any more appropriate when directed toward an institutionalized elder than when it was directed toward a fellow community elder. Additionally, elder targets of patronizing speech were perceived to be less competent and active/potent than those receiving neutral speech, implicating a tendency to blame the victim of patronizing speech. Again, blaming the victim was not more prevalent when the elder target was in an institutional setting versus a community setting. The lack of effect for the elder target's place of residence does not support the hypotheses of this study and contrasts what would be expected by the Communication Predicament Model of Aging. However, the manipulation of this variable was most likely not salient enough to produce the predicted effect. 


\section{REFERENCES}

Ashburn, G., \& Gordon, A. (1981). Features of a simplified register in speech to elderly conversationalists. International Journal of Psycholinquistics, 8. 7-31.

Baltes, M. M., Burgess, R. L., \& Stewart, R. B. (1980). Independence and dependence in self-care behaviors in nursing home residents: An operant-observational study. International Journal of Behavioral Development, 3 , 489-500.

Baltes, M. M., Honn, S., Barton, E. M., Orzech, M. J., \& Lago, D. (1983). On the social ecology of dependence and independence in elderly nursing home residents: $A$ replication and extension. Journal of Gerontology, 38, 556-564.

Baltes, M. M., \& Reisenzein, R. (1986). The social world in long-term care institutions: Psychological control toward dependency. In M. M. Baltes, \& P. B. Baltes (Eds.), The psychology of control and aging (pp. 315-343). Hillsdale, NJ: Erlbaum.

Baltes, M. M., \& Skinner, E. A. (1983). Cognitive performance deficits and hospitalization: Learned helplessness, instrumental passivity, or what? Comment on Raps, Peterson, Jonas, and Seligman. Journal of Personality and Social Psychology, 45. 1013-1016.

Barton, E. M., Baltes, M. M., \& Orzech, M. J. (1980). Etiology of dependence in older nursing home residents during morning care: The role of staff behavior. Joumal of Personality and Social Psychology, 38, 423-431. 
Brooke, V. (1989). How elders adjust: Through what phases do newly admitted residents pass? Geriatric Nursing, 10 , 126-128.

Cai, D., Giles, H., \& Noels, K. (1998). Elderly perceptions of communication with older and younger adults in China: Implications for mental health. Journal of Applied Communication Research.26,32-51.

Caporael, L. R. (1981). The paralanguage of caregiving: Baby talk to the institutionalized aged. Joumal of Personality and Social Psychology_40, 876-884.

Caporael, L. R., Lukaszewski, M. P., \& Culbertson, G. H. (1983). Secondary baby talk: Judgments by institutionalized elderly and their caregivers. Joumal of Personality and Social Psychology, 44, 746-754.

Coupland, N., Coupland, J., Giles, H., \& Henwood, K. (1988). Accommodating the elderly: Invoking and extending a theory. Language in Society, 17, 1-41.

Culbertson, G. H., \& Caporael, L. R. (1983). Baby talk speech to the elderly: Complexity and content of messages. Personality and Social Psychology Bulletin. 9 , 305312.

Dolinsky, E. H. (1984). Infantilization of the elderly: An area for nursing research. Journal of Gerontological Nursing, 10 , 12-19.

Edwards, H., \& Noller, P. (1993). Perceptions of overaccommodation used by nurses in communication with the elderly. Journal of Lanquage and Social Psychology 12. 207-223. 
Folstein, M. F., Folstein, S. E., \& McHugh, P. R. (1975). Mini-Mental State: A practical method for grading the cognitive state of patients for the clinician. Joumal of Psychiatric Research, 12, 189-198.

Foreman, M. D. (1987). Reliability and validity of mental status questionnaires in elderly hospitalized patients. Nursing Research, 36, 216-220.

Giles, H., Coupland, N., Coupland, J., Williams, A., \& Nussbaum, J. (1992). Intergenerational talk and communication with older people. International Journal of Aging and Human Development. 34, 271-297.

Giles, H., Fox, S., \& Smith, E. (1993). Patronizing the elderly: Intergenerational evaluations. Research on Language and Social Interaction, 26, 129-149.

Giles, H., \& Williams, A. (1994). Patronizing the young: Forms and evaluations. International Journal of Aging and Human Development, 39, 33-53.

Haglund, R. M. J., \& Schuckit, M. A. (1976). A clinical comparison of tests of organicity in elderly patients. Journal of Gerontology, 31, 654-659.

Harwood, J., Giles, H., Fox, S., Ryan, E. B., \& Williams, A. (1993). Patronizing young and elderly adults: Response strategies in a community setting. Research Reports, 21, 211-226.

Hummert, M. L. (1994). Physiognomic cues to age and the activation of stereotypes of the elderly in interaction. International Journal of Aging and Human Development, 39, 5-19.

Hummert, M. L., \& Shaner, J. L. (1994). Patronizing speech to the elderly as a function of stereotyping. Communication Studies, 45, 145-158. 
Hummert, M. L., Shaner, J. L., Garstka, T. A., \& Henry, C. (1998).

Communication with older adults: The influence of age stereotypes, context, and communicator age. Human Communication Research, 25, 124-151.

Joiner, C. M., \& Freudiger, P. T. (1993). Male and female differences in nursing home adjustment and satisfaction. Journal of Gerontolopical Social Work, 20, 71-85.

Kemper, S., Vandeputte, D., Rice, K., Cheung, H., \& Gubarchuk, J. (1995).

Speech adjustments to aging during a referential communication task. Journal of Language and Social Psychology, 14, 40-59.

Lester, P. B., \& Baltes, M. M. (1978). Functional interdependence of the social environment and the behavior of the institutionalized aged. Journal of Gerontolopical Nursing, 4, 23-27.

McGee, J., \& Barker, M. (1982). Deference and dominance in old age: An exploration in social theory. International Journal of Aging and Human Development, 15. 247-262.

Pfeiffer, E. (1975). A short portable mental status questionnaire for the assessment of organic brain deficit in elderly patients. Journal of the American Geriatrics Society, 23, 433-441.

Pruchno, R. A., Smyer, M. A., Rose, M. S., Hartman-Stein, P. E., \& HendersonLaribee, D. L. (1995). The Gerontologist, 35, 622-629.

Ryan, E. B., Bourhis, R. Y., \& Knops, U. (1991). Evaluative perceptions of patronizing speech addressed to elders. Psychology and Aging, 6, 442-450. 
Ryan, E. B., \& Cole, R. (1990). Evaluative perceptions of interpersonal communication with elders. In H. Giles, N. Coupland, \& J. Wiemann (Eds.), Communication, health, and the elderly (pp. 172-190). Manchester: University of Manchester Press.

Ryan, E. B., Giles, H., Bartolucci, G., \& Henwood, K. (1986). Psycholinguistic and social psychological components of communication by and with the elderly. Language and Communication, 6, 1-24.

Ryan, E. B., Hamilton, J. M., \& See, S. K. (1994). Patronizing the old: How do younger and older adults respond to baby talk in the nursing home? International Joumal of Aging and Human Development, 39, 21-32.

Ryan, E. B., Hummert, M. L., \& Boich, L. H. (1995). Communication predicaments of aging: Patronizing behavior toward older adults. Joumal of Lanquage and Social Psychology, 14, 144-166.

Ryan, E. B., Kennaley, D. E., Pratt, M. W., \& Shumovich, M. A. (1996, May). Patronizing speech and assertive responses in the nursing home: Evaluative perceptions by staff, residents, and community seniors. Paper presented at the meeting of the International Conference on Communication, Aging, and Health, Kansas City, MO.

Ryan, E. B., Maclean, M., \& Orange, J. B. (1994). Inappropriate accommodation in communication to elders: Inferences about nonverbal correlates. International Journal of Aging and Human Development, 39, 273-291. 
Ryan, E. B., Meredith, S. D., \& Shantz, G. B. (1994). Evaluative perceptions of patronizing speech addressed to institutionalized elders in contrasting conversational contexts. Canadian Journal on Aging, 13, 236-248.

Sachweh, S. (1998). Granny darling's nappies: Secondary babytalk in German nursing homes for the aged. Journal of Applied Communication Research. 26, 52-65.

Spasoff, R. A., Kraus, A. S., Beattie, E. J., Holden, D. E. W., Lawson, J. S., Rodenburg, M., \& Woodcock, G. M. (1978). A longitudinal study of elderly residents of long-stay institutions: Early response to institutional care. The Gerontolopist, 18, 281292.

Stewart, M. A., \& Ryan, E. B. (1982). Attitudes toward younger and older adult speakers: Effects of varying speech rates. Journal of Lanquage and Social Psychology, 1. 91-109.

Thimm, C., Rademacher, U., \& Kruse, L. (1998). Age stereotypes and patronizing messages: Features of age-adapted speech in technical instructions to the elderly. Joumal of Applied Communication Research, 26, 66-82.

Whitbourne; S. K., Culgin, S., \& Cassidy, E. (1995). Evaluation of infantilizing intonation and content of speech directed at the aged.International Journal of Aging and Human Development, 41, 109-116.

Wood, L. A., \& Ryan, E. B. (1991). Talk to elders: Social structure, attitudes, and forms of address. Ageing and Society, 11, 167-187. 


\section{APPENDIX A}

Dialogues for the Patronizing and Neutral Vignettes

\section{Neutral Vignette--Actress Pair A}

Nurse approaches elder and sits down next to her, speaking at the same eye level. Nurse A: Good moming, Mrs. Johnson. It's good to see you again. How are you today? Elder A: I am feeling all right. How are you?

Nurse A: I'm fine, thanks. Listen, that's a lovely outfit you've got on.

Elder A: Thank you. Looks like we're really going to have a hard flu season this year. Nurse A: Yeah, it's a good thing you're coming in for your flu shot early to prepare for it. Are you ready?

Elder A: As ready as anybody can be for a shot in the arm.

Nurse A: Okay, then, let's go on back to my office. (As they are walking back to the nurse's office) Listen, if you start to develop any flu symptoms or anything, give me a call and feel free to come in.

Elder A: All right. 


\section{Neutral Vignette--Actress Pair B}

Nurse approaches elder and sits down next to her, speaking at the same eye level.

Nurse B: Hello, Mrs. Johnson. How are you doing today?

Elder B: Oh, I'm just fine, thank you. And how are you?

Nurse B: I'm doing just fine. That's a lovely outfit you've got on.

Elder B: Oh, well, thank you. $\mathrm{Uh}$, looks like we're going to have a pretty rough flu season ahead of us.

Nurse B: Yeah, it's really a good idea that you decided to come on in and get your flu shot early. Are you ready?

Elder B: As ready as anyone is for a shot in the arm.

Nurse B: Okay, let's go back to my office. (As they are walking back to the nurse's office) And let me say that if you should develop any symptoms of the flu or any other problems, please come on back and see me.

Elder B: All right, all right. 


\section{Patronizing Vignette-Actress Pair A}

Nurse approaches elder and remains standing throughout the conversation while the elder remains seated. All speech by the nurse is a higher pitch and is more exaggerated in intonation than the neutral vignette.

Nurse A: Good morning, Honey (term of endearment versus title and surname). How are we (exclusive "we") today (nurse pats elder's shoulder-demeaning nonverbal behavior)? It's good to see you again.

Elder A: I'm feeling all right. How are you?

Nurse A: I'm just fine. Isn't that a cute little outfit (infantilization and demeaning emotional tone) you've got on (nurse touches elder's cuff of jacket and then her shoulder --demeaning nonverbal behavior)!

Elder A: Thank you. Looks like we're really going to have a hard flu season ahead.

Nurse A: Well, don't you worry about that, Honey (term of endearment versus title and surname). We're going to get you all fixed up (exclusive "we" and demeaning emotional tone). Are we ready (exclusive "we")?

Elder A: As ready as anybody can be for a shot in the arm.

Nurse A: (Nurse gently takes elder's arm to help her up) That's a good girl (demeaning emotional tone). Well, let's go on back to my office. (As they walk back to the nurse's office) Listen now, if you get any flu symptoms or any other problems, you come back in and I mean that (overparenting).

Elder A: All right. 


\section{Patronizing Vignette-Actress Pair B}

Nurse approaches elder and remains standing throughout the conversation while the elder remains seated. All speech by the nurse is a higher pitch and is more exaggerated in intonation than the neutral vignette.

Nurse B: Good morning, Honey (term of endearment versus title and surname). How are we doing today (exclusive "we")?

Elder B: Oh, I'm all right. And how are you?

Nurse B: I'm doing just fine. That's a cute little outfit you've got on (infantilization and demeaning emotional tone)!

Elder B: Oh, thank you. It looks like we're going to have a rough flu season ahead of us this year.

Nurse B: Well, don't you worry your little head about it (nurse pats elder's shoulderdemeaning nonverbal behavior). We're going to take care of you (exclusive "we" and demeaning emotional tone). Are you ready to come on back?

Elder B: Well, as ready as anyone is for a shot in the arm.

Nurse B: (Gently taking the elder's arm to help her up) Okay, that's a good girl (demeaning emotional tone). Now, let's go back to my office. (As they walk back to the nurse's office) If you have any problems after you've had your shot, you be sure to give me a call (overparenting) and we'll take care of you (demeaning content and emotional tone).

Elder B: All right.

Nurse B: Okay? 


\section{VITA}

The author, Tammi Rae La Tourette, is the wife of Brett Robert La Tourette, and the daughter of Edward and Janet Liefke. She was born September 17, 1973, in Portland, Oregon.

Her elementary education and secondary education were obtained in the public schools of Orange and San Diego counties in southern California. She graduated from Fallbrook Union High School in June, 1991.

In July, 1991, she entered Palomar College in San Marcos, California, where she finished her general education requirements. She completed her junior and senior years at California State University San Marcos, where she graduated cum laude with a Bachelor of Arts in Psychology in May, 1995.

In August, 1996, she entered the doctoral program in clinical psychology at the University of Louisville, and was granted a graduate assistantship.

Throughout her undergraduate and graduate education, she has been involved in several research projects and has had the opportunity to co-author two papers and two poster presentations, and author one paper (research proposal) presentation. She has also been actively involved in clinical work with children, as well as young, middle-aged, and elderly adults. Additionally, she is a member of several professional organizations including the Gerontological Society of America, the American Psychological 
Association, the American Society on Aging, and the Kentucky Psychological Association.

Her professional goals include a clinical and academic career, working with the elderly population, focused on caregiving issues both in the home and in nursing homes. 